NASA Technical Memorandum 89812

AIAA-87-2111

\title{
Two-Dimensional Nozzle Plume Characteristics
}

(NASA-TH-89812) TRO-CIUENSICAAI NOZZLE ELUME CHAGACTERISIICS (NASA) 23 F CSCL 01A
N $87-18540$

Unclas

G3/02

43838

Uwe H. von Glahn

Lewis Research Center

Cleveland, Ohio

Prepared for the

23rd Joint Propulsion Conference

cosponsored by the AIAA, SAE, ASME, and ASEE

San Diego, California, June 29-July 2, 1987

\section{nush}


Uwe $H$. von $G 1$ ahn

National Aeronautics and Space Administration

Lewis Research Center

Cleveland, Ohio 44135

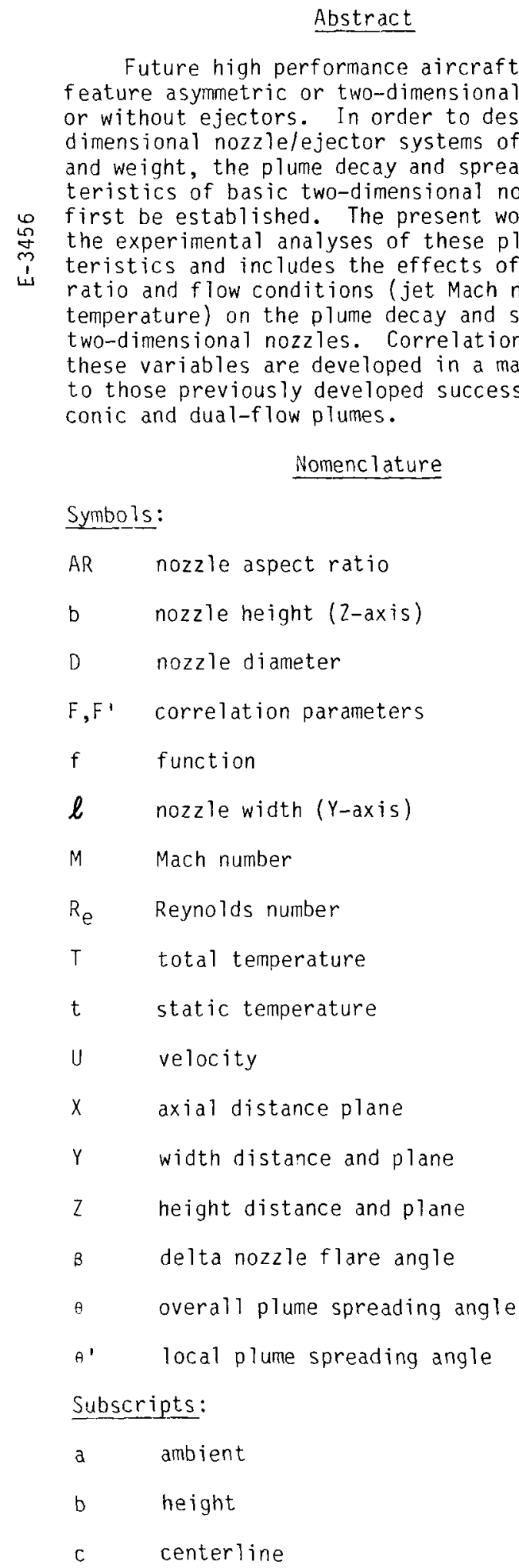

$\begin{array}{ll}D P & \text { departure point } \\ e & \text { effective } \\ \text { init } & \text { initial mixing region } \\ j & \text { jet } \\ \ell & \text { width } \\ \text { mix } & \text { fully mixed region } \\ R & \text { radial } \\ s & \text { start or initiation } \\ t & \text { temperature } \\ t r a n & \text { transition region } \\ v & \text { velocity } \\ x, y, z & \text { axis directions } \\ 0.5 & \text { half velocity or half temperature }\end{array}$

\section{Introduction}

Currently some high performance aircraft, such as the F-111 and SR-71, are equipped with axisymmetric nozzle/ejector engine exhaust systems. The ejectors are used to mix the engine exhaust flow with ambient air in order to provide thrust augmentation under some operating conditions. Future high performance aircraft will likely feature asymmetric or two-dimensional nozzles with or without ejectors. The future use of asymmetric nozzle systems includes, among other considerations, enhanced aircraft maneuvering capability.

Two-dimensional nozzle systems provide inherentiy more rapid plume velocity and temperature decay with axial distance from the nozzle exit plane than do conic nozzles. Similarly, the plume spreading is more rapid for a two-dimensional nozzle in the nozzle height dimension and less in the nozzle width dimension compared with that for a conic nozzle operating at equal flow and thrust conditions. Two-dimensional nozzles when coupled with two-dimensional ejectors have a greatly reduced shroud length compared with axisymmetric nozzle/ejector systems due to the benefits resulting from the more rapid plume decay of the twodimensional plume compared with the conic plume.

For design purposes, the velocity/temperature decay and the radial spreading of asymmetric exhaust plumes must be taken into account in order to provide acceptably small, efficient and light weight asymmetric ejector systems. By taking into consideration the transition duct design from the axisymmetric geometry at the engine turbine exit face to the asymmetric geometry at the nozzle exit plane as well as the aircraft external fuselage 
size and shape constraints, single engine twodimensional nozzle aspect ratios will most likely be in the range of 3 to 6 . Side-by-side dual engine installations therefore will have effective aspect ratios of twice those of the single engine aspect ratios, or 6 to 12 .

In order to design efficient, rapid-mixing two-dimensional nozzle/ejector systems, the plume decay and spreading characteristics of basic twodimensional nozzles must first be established. Consequently, the present work deals with the plume characteristics of two-dimensional nozzles without ejectors. Included in the study are the effects of nozzle aspect ratio and flow conditions including jet Mach number and temperature on the plume decay and spreading of two-dimensiona? nozzles. Correlation procedures including these variables are developed in a manner similar to those developed successfully for conic and dualflow nozzles. $1-3$

\section{Background}

Genera 1

Studies of two-dimensional orifice/nozzle plume characteristics haye been available in the literature for over $50 \mathrm{yr}$. The early work was generally of more academic interest than of practical application to aircraft. Consequently, much of the early experimental work was conducted with orifices rather than nozzles. Sketches of various orifice types used in these studies are summarized in Fig. 1. As will be shown later, the type of orifice used can significantly affect the plume velocity and temperature characteristics, particularly when compared with nozzle data.

The basic orifices used in the literature include square-edge, sharp-edge and round-edge types. ${ }^{-9}$ In some studies, two-dimensionsal channels were used that terminated as a wall orifice. ${ }^{7,9-11}$ In other studies, the flow was further channeled between two parallel plates attached to the long sides of the wall orifice or wall nozzle.12-15 Finally, in the free-standing nozzles used in several studies, only two sides (long dimension of the nozzle) were contracting while the other two sides (short dimension) were either parallel or diverging. 16-21

The literature includes consideration of nozzle aspect ratios as high as 40 (blown flap applications). However, interest in more recent years has centered more on nozzle aspect ratios of 3 to 10 .

In general, the early data were obtained with low jet Mach numbers and cold flow or relatively low stream temperatures. More recently, limited data for jet exhaust velocities up to low supersonic speeds and temperatures up to about $600 \mathrm{~K}$ have become available. These data were usually obtained with aspect ratios of 6 or less. Furthermore, much of the recent data have been obtained with nozzles rather than orifices, thereby being of more practical value to the aircraft engineering community.

\section{Plume Flow Regions}

It has been generally accepted that a twodimensional nozzle (or orifice) plume consists of three main regions shown schematically in Fig. 2 and described as follows:

(1) An initial mixing region defined in the literature as the potential core region. In this region, the nozzle centerline velocity is essentially constant within the inner mixing boundaries and with the axial extent of the region being determined by the nozzle half-height, $b / 2$, in the Z-direction.

(2) A transition region also defined in the literature as the characteristic decay region. In this region, the centerline velocity decays with increasing axial distance but at each axial station, $x$, the local velocity within the inner mixing boundary is constant in the Y-direction. The axial extent of the transition region is function of the nozzle (orifice) half-width, $\ell / 2$. Note that a square nozzle does not have a transition region because the plume decay is identical in both the $Y$ - and $Z$-directions.

(3) The final region is defined as the fullymixed or axisymmetric-type flow region. In this region, the plume peak velocity always occurs at the nozzle centerline; i.e., there is no constant velocity component in the Y-direction.

The plume temperature decay characteristics are similar to those described in the preceding discussion of the plume velocity decay. The axial temperature decay, however, is initiated earlier (closer to the nozzle exit plane) than that of the velocity as shown schematically in Fig. 3. As a consequence, the plume radial temperature spreads more rapidly than the radial velocity, also shown in Fig. 3 .

\section{Overall Plume Decay Characteristics}

A schematic sketch of the typical twodimensional nozzle plume centerline decay with axial distance is shown in Fig. 4 together with that for a conic (or square) nozzle plume. It is apparent that the two-dimensional nozzle velocity decays faster than that for the circular nozzle under equal flow conditions. In the initial mixing region, the shapes of the two curves, once the decay has begun, is the same although the absolute values are different. Also, in the fully-mixed region, the slope of both curves follow an $x^{-1}$ decay rate. Although not shown in the figure, the plume centerline temperature decay curve is similar to that for the velocity decay curve shown in Fig. 4 except that the temperature decay curve is displaced to the left of the velocity decay curve indicating an earlier decay initiation.

In Fig. 5 is shown a schematic sketch of the effect of two-dimensional nozzle aspect ratio on the plume centerline velocity decay characteristics. With increasing aspect ratio, the initiation of the decay curves shifts to increasingly smaller values of axial distance from the nozzle exit plane. Similar trends are obtained for the variation of plume temperature decay curves with nozzle aspect ratio. However, the plume temperature decay, for a given aspect ratio, begins sooner axially than that for the plume velocity decay as noted earlier. Also, as previously noted, the plume temperature spreading rate is greater than that for the plume velocity. 
Orifice/Nozzle Plume Decay Comparisons

In some of the plume flow regions, the rate of plume velocity decay differs between orifice types and between orifices and nozzles. The differences are most apparent in the initial and transition mixing regions of the plume. Three primary factors contribute to these plume mixing differences, two of which are shown in Fig. 6 . These factors are: (1) the flow coefficient which varies with orifice-edge shape (Fig. 1) and contributes to differences in the size and shape of the orifice vena contracta and which is not present with nozzles, (2) the differences in the inflow to the jet stream from the surrounding medium due to the orifice "wall," and (3) the flow profile differences (nonuniformity) at the orifice exit plane when a tubular or channel orifice is used with or without a wall at the exit plane. All of these factors affect the orifice plume velocity decay, particularly in the regions nearest the orifice exit plane.

Some examples of the effect of some of the preceding factors on the orifice plume centerline velocity decay are shown in Fig. 7. In Fig. 7(a), the centerline velocity decay for a thin squareedge orifice and a nozzle are shown, both having an aspect ratio of 6 . The shift in the orifice velocity decay data to the left of the nozzle velocity decay data is quite evident. In Fig. 7(b), orifice velocity decay data for a nominal aspect ratio of 12 are shown for square- and round-edge orifices and a nozzle. It is apparent that both sets of orifice data are shifted to the left of the nozzle data (closer to the exit plane), with the square-edge orifice data showing a greater shift than the round-edge orifice data.

Similar orifice/nozzle plume centerline temperature decay data to the velocity decay data are not available. However, because of the general relationship between plume velocity and temperature decay, as will be shown later, similar trends would be expected.

\section{Nozzle Plume Centerline Decay Trends}

Velocity

Cold flow. Published data on the cold-flow centerline velocity decay for two-dimensional nozzles are shown in Fig. 8. The velocity decay, $U_{c} / U_{j}$, is plotted as a function of $x\left(t_{j} / t_{a}\right)^{0.25} / D_{e} \sqrt{1+M_{j}}$, a parameter previously found successful in correlating conic and dual-flow nozzle plume decay data. $1-3$ Also shown in the figure is the conic nozzle centerline velocity decay curve from Ref. 1. It is apparent from these data that the nozzle plume centerline velocity decay is initiated increasingly sooner with increasing nozzle aspect ratio, as shown schematically in Fig. 5 .

If the nozzle short sides, b, are flared at an angle, $\beta$ (Delta nozzles in Refs. 18 and 19) the centerline velocity decay is initiated even earlier than that for a similar nonflared nozzle, increasing as a tunction of the flare angle. Representative Delta nozzle centerline velocity decay data are shown in Fig. 9.

Heated flow. The effect of heating a twodimensional nozzle jet on the plume centerline velocity decay is shown in Figs. 10 and 11 . In
Fig. 10, the parameters used correlate the data well for a two-dimensional nozzle with an aspect ratio of 5 and $B=0^{\circ}$ over the range of data shown. With a Delta nozzle (Fig. 11) it is evident that the transition region with a heated jet can occur farther downstream than that with cold flow. Also, the fully mixed region with heated flow is displaced farther from the conic nozzle decay curve than that with cold flow. In the initial mixing region, there is no effect of jet temperature on the plume centerline velocity decay when plotted in terms of the correlation parameters shown in Figs. 10 and 11 .

\section{Temperature}

The plume centerline static temperature decay is shown plotted in Fig. 12 as a function of the same abscissa parameter as that used for the velocity decay in Fig. 11. The data shown in Fig. 12 are for a Delta nozzle with $\beta=5^{\circ}$. Also shown in the figure is the plume centerline static temperature decay curve for a conic nozzle. 1 In general, the data trend is similar to that discussed in the previous section for the velocity decay.

\section{Plume Centerline Decay Correlation}

The plume centerline decay characteristics were correlated separately for the three plume decay regions shown previously in Fig. 2 .

Veiocity

Initial mixing region. For simple twodimensional nozzle $(\beta=0)$, the plume centerline velocity decay data were correlated by a form parameter given by $[1+0.15(A R-1)]$ which is a multiplication factor for the abscissa term $x\left(t_{j} / t_{a}\right)^{0.25} / D_{e} \sqrt{1+M_{j}}$ shown in Fig. 12. When the short dimension of the nozzle is flared, as for the Delta nozzles, an additional term accounting for the flare angle was required. This parameter was determined to be expressed by $\left[1+5.5(\tan \beta)^{0.67}\right]$. Consequent $7 y$, the general correlation parameter for two-dimensional nozzles in the initial mixing region is given by the following equation:

$$
F_{\text {init }}=1+0.15(A R-1)\left(1+5.5(\tan B)^{0.67}\right)
$$

The correlated centerline velocity decay data in the initial mixing region are shown in Figs. 13 and 14 for conventional two-dimensional and Delta nozzles, respectively. Also shown in the figures, for reference, is the conic nozzle centerline velocity decay curve from Ref. 1 . The good correlation of the conventional two-dimensional and Delta nozzle data in the initial mixing region with the conic nozzle curve by means of $\mathrm{Eq}$. (1) is apparent.

Transition region. The correlation of both the conventional two-dimensional and flared nozzle velocity decay data in the transition region requires the prediction of the start of this region, herein designated as the departure point, relative to the conic nozzle centerline velocity decay curve and the establishment of the decay curve downstream of the departure point. 
The transition region departure point from the conic nozzle curve was determined to be functions of the nozzle aspect ratio, the nozzle flare angle, $\beta$, and the jet-to-ambient total temperature ratio. The following equation was developed with which to calculate the departure point, $X_{D P}$, in terms of the abscissa variables used in Figs. 12 and 13: (2)

$$
\begin{aligned}
& x_{D P, v}=\left[x\left(t_{j} / t_{a}\right)^{0.25}\left(F_{i n i t}\right) / D_{e} \sqrt{1+M_{j}}\right]_{D P, v} \\
& =25\left[1+20(\tan B)^{3}\right]\left[\sqrt{T_{j} / T_{a}(A R-1)}\right]\left[1+\left(0.33 / M_{j}\right)^{4}\right]^{-1}
\end{aligned}
$$

The slope of curves through the data in the transition region is generally accepted as being a function of $x-0.5$. For the available twodimensional data in the transition region, this results in the following correlation equation:

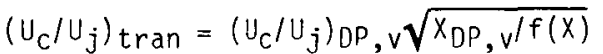

where $f(x)$ is given by $\left[x\left(t_{j} / t_{a}\right)^{0.25} / 0 e \sqrt{1+M_{j}}\right] F_{i n i t}$ and is equal to or greater than $X_{D P, V}$.

Equation (3) is valid when two-dimensional departures occur in the region where the conic nozzle centerline velocity decay curve slope is equal to or $>0.5$. When the slope of the conic nozzle velocity decay curve is $<0.5$, the exponent of $X_{D P, V} / F(X)$ in $E q$. (3) must be reduced because the slope of the data will be <0.5. Similar trends were encountered in Refs. 2 and 3 and modifications to the equations were included. However, this modification was not included herein because practical aircraft applications of two-dimensional nozzles would most likely be the range where a slope or exponent of 0.5 applies. It should also be noted that for nonflared two-dimensional nozzles, the $\beta$-term drops out of Eq. (2).

The correlated two-dimensional nozzle centerline velocity decay data in the transition region are shown in Figs. 15 and 16 for nozzles with and without flared sides, respectively. The solid symbols in the figures indicate the calculated departure points obtained by use of Eq. (2). In general, the calculated departure points and curves based on Eqs. (2) and (3), respectively represent the data quite well. It should be noted that the flared nozzle data with a flare angle of $30^{\circ}$ did not show any departure from the conic nozzle curve over the range of data available.

Fully-mixed region. The plume centerline velocity decay data in the fully mixed region was correlated by a parameter given by:

$$
F_{V, \text { mix }}=1+\left[6(1-1 / A R)^{6}\left(T_{j} / T_{a}\right)\right] / A R
$$

In $\mathrm{Fig} .17$, the correlated data are shown together with the conic nozzle plume decay curve. 1 Good agreement is apparent for both the conventional two-dimensional nozzles and the $5^{\circ}$ flare angle Delta nozzle. Note that the correlation parameters in $\mathrm{Eq}$. (4) do not appear to require a 8 -term suggesting that in the fully-mixed region the centerline velocity decay is independent of the nozzle flare angle. However, this may be fortuitous since the $30^{\circ}$ flare angle data did not depart from the conic nozzle curve in the transition region, as mentioned in the previous section. Consequently, there are no high-flare angle data available in the fully-mixed region to support or refute the assumption that this region is independent of flare angle.

\section{Static Temperature}

Initial mixing region. Two-dimensional nozzle plume centerline temperature decay data are very limited. While some such data are available for orifices, these data in this flow region are not compatible with those for nozzles as discussed earlier. Correlated available data are shown in $\mathrm{Fig} .18$ for two nozzle configurations. Also shown in the figure is the conic nozzle curve. The parameter, Finit, used to correlate these data is the same as that used to correlate the plume centerline velocity decay data and is given by $\mathrm{Eq}$. (1). The data are seen to be reasonably well correlated by this parameter.

Transition region. The plume centerline temperature decay in the transition reqion for the two sets of data used for Fig. 18 are shown in Fig. 19. The departure points from the conic nozzle decay curve were calculated using essentially Eq. (2), but without the inclusion of the temperature departure points in the transition region is given by:

$$
\begin{aligned}
& x_{D P, t}=\left[x\left(t_{j} / t_{a}\right)^{0.25}\left(F_{\text {init }}\right) / D_{e} \sqrt{1+M_{j}}\right]_{D P, t} \\
& =25\left(1+20(\tan B)^{3}\right] / \sqrt{A R-1}\left[1+\left(0.033 / M_{j}\right)^{4}\right]
\end{aligned}
$$

The slope of the temperature transition region curve in the range of the available data again is given by an exponent of 0.5 , as was the case for the velocity curve in the transition region. For the available data in the transition region, this results in the following correlation equation:

$$
\begin{aligned}
& {\left[\left(t_{c}-t_{a}\right) /\left(t_{j}-t_{a}\right)\right]_{t r a n}=} \\
& {\left[\left(t_{c}-t_{a}\right) /\left(t_{j}-t_{a}\right)\right]_{D P, t}\left[\sqrt{x_{D P, t} / f(x)}\right]}
\end{aligned}
$$

where $f(x)$ is given by $\left[x\left(t_{j} / t_{a}\right)^{0.25 / D_{e}}\right.$ $\left.\sqrt{1+M_{j}}\right]$ Finit and is equal to or greater than verification in the application of $\mathrm{Eq}$. (5) for other nozzle aspect ratios and flow conditions.

Fully-mixed region. As in the case of the plume centerline velocity decay, while the initial and transition mixing region decay rates differed for orifices and nozzles, the decay in the fullymixed region was substantially the same for these configuration types. Because of this fact and that only plume centerline temperature decay data for a Delta nozzlel8 was available in this flow region, orifice data are also used herein to provide a measure of confidence in the present correlation procedure.

The plume centerline temperature decay data were correlated in substantially the same manner as the velocity decay data; however, an exponent of 0.5 on the temperature ratio was used in place 
of 1.0 as in Eq. (4). Thus, the plume centerline temperature decay in the fully-mixed region is given by:

$$
F_{t, \operatorname{mix}}=1+\left[6(1-1 / A R)^{6}\left(T_{j} / T_{a}\right)^{0.5}\right] / A R
$$

The correlated plume centerline temperature decay data are shown in Fig. 20 together with the reference conic nozzle curve of Ref. 1. In general, good correlation for both nozzle and orifice data has been obtained.

\section{Plume Centerline Velocity/Static Temperature}

Decay Relationship

A unique relationship exists between the plume centerline velocities, $U_{C} / U_{j}$, and the static temperatures, $\left(t_{c}-t_{a}\right) /\left(t_{j}-t_{a}\right)$, at all axial stations downstream of the nozzle exit plane. ${ }^{1}$ This relationship, according to Ref. 1 , is given by the following equation:

$\left(t_{c}-t_{a}\right) /\left(t_{j}-t_{a}\right)=\left[1+4.3\left\{\left(U_{c} / U_{j}\right) 8-1\right\}\right]-0.125$

Equation (8) applies to all single-stream nozzle plumes, and with the inclusion of the proper geometry variables to two-stream nozzle plumes. Finally, Eq. (8) is also valid for excited jet plumes.

In Fig. 21, the plume centerline static temperature ratio, $\left.\left(t_{c}-t_{a}\right) / t_{j}-t_{a}\right)$, is shown plotted as a function of the plume centerline velocity ratio $\left(U_{C} / U_{j}\right)$, for various axial distances downstream of the nozzle exit plane. The curve shown in the figure was generated by the use of Eq. (8). All the data shown in the figure group about this curve and are well within the scatter expected from experimental data of this nature. Note that although different plume decay results are obtained for orifices and nozzles in the initial- and transition-flow regions of the plume as stated earlier, both configuration-type sets of data correlate on this plot.

As a consequence of the static temperatureto-velocity ratio relationship shown in Fig. 21 , plume centerline static temperature decay curves can be generated for two-dimensional nozzles of various nozzle aspect ratios when only the plume centerline velocity decay data from cold flow experimental studies are available as a function of axial distance from the nozzle exit plane.

\section{Radial Profiles}

Radial velocity and temperature profiles of conic nozzle jet plumes are frequently separated into two regions. The first region includes the radia? profiles in the vicinity of the core flow while the second region includes the radial profiles downstream of the core flow. In the latter region, the radial profiles are referred to as "similarity profiles."

For two-dimensional nozzles, two core: regions exist as depicted in Fig. 2. The first of these regions is associated with the nozzle height dimension, $Z$, and the second of these regions is associated with the nozzle width dimension, $Y$. In these core regions similarity profiles are generally not considered to exist because the profile has a uniform segment before decaying in the radial direction, as shown schematically in Fig. 22. This segment decreases in radial distance with increasing axial distance until the width apex is reached (Fig. 2). It is obvious that this apparent nonsimilarity region for both velocity and temperature becomes increasingly more important with increasing nozzle aspect ratios. However, it will be shown later that by considering only the radial decay segment of the radial profile that similarity does exist in both $Y$ - and Z-directions. Also it will be shown that similarity in the core applies to both the velocity and the static temperature profiles.

\section{Core Regions}

In the height dimension, $z$, of two-dimensional nozzles few, if any, plume radial velocity and temperature measurements have been made. However, some plume radial measurements have been made in the width dimension, Y. Representative data of such measurements are shown in Fig. 23 for both velocity and temperature radial profiles. The data shown are in conventional terms of $U_{R} / U_{C}$ as a function of $Y / Y_{0}$. The start of the radial decay is designated by the term $\left(Y / Y_{0.5}\right)_{S}$.

In Fig. 23(a), radial velocity decay data ${ }^{19}$ are shown for a two-dimensional nozzle with an aspect ratio of 6 . The radial velocity decay at the $X / D_{e}$ station of 2 is estimated to start at $Y / Y_{0} .5$ equal to 0.3 , which is the $\left(Y / Y_{0.5}\right)_{s}$ value for this case. In Fig. $23(\mathrm{~b})$, radial temperature decay data are shown for an orifice with an aspect ratio of 40 . The data shown are for $X / D_{e}$ values of $2.8,5.6$, 16.8. For these sets of data the radial decay starts are estimated at $\left(Y / Y_{0.5}\right)_{S}$ values of $0.8,0.64$, and 0.05 for the preceding three $\mathrm{X} / \mathrm{D}_{\mathrm{e}}$ stations, respectively.

The data sets shown in Fig. 23 are now plotted in terms of $\left(Y / Y_{0}, 5\right)-\left(Y / Y_{0}, 5\right)$ in Fig. 24 except for the temperature data at $\times 10$ of 16.8 which is already almost a similarity profile. This results in only the actual radial decay portion of the profiles being shown. Also shown in the figure are the conic nozzle radial decay curves from Ref. 1. Good agreement between the two-dimensional configurations and the conic nozzle curve is evident for both the radial velocity and radial temperature decay. Thus, when analyzed in this manner similarity profiles are established in the core regions.

Transition and Fully-Mixed Flow Regions

In the transition and fully-mixed flow regions of two-dimensional nozzles/ orifices similarity radial profiles are obtained in both the height ( $Z$ ) and width $(Y)$ dimensions of the plume.

In Fig. 25(a) typical plume radial velocity profjles are shown for a nozzle with an aspect ratio of $6^{19}$ in the height dimension of the nozzle. Similar data are shown in Fig. 25(b) for the width dimension of the nozzle. The furves shown in the figure are for a conic nozzle. Additional data in Refs. 23 and 8 include both radial velocity and temperature profiles for a nozzle $(A R, 6)$ and an orifice (AR, 10), respectively. These data are reproduced in Figs. 26 and 27 , together with the similarity profile curves for a conic nozzle. 1 It is apparent that the conic nozzle similarity profile curves represent the radial velocity and temperature decay for two-dimensional nozzles and 
orifices satisfactorily in both the height and width dimensions of the transition and fully mixed flow regions of the plume.

Spreading Characteristics of Two-Dimensional Plumes

A schematic sketch of the spreading characteristics and reference dimensions for two-dimensiona? plumes is shown in Fig. 28. The spreading of twodimensional plumes is a strong function of the configuration type; i.e., nozzle or orifice. Initial studies in Ref. 7 indicated significant differences in the plume spreading between a sharp-edge orifice and a rectangular channel orifice having a channel length of 50 channel heights, both having an aspect ratio of 10 . Further work ${ }^{9}$ of measurements of the mean flow field corroborated the results of the initial study. Typical plume spreading of the preceding two configuration types is shown in Fig. 29. The plume spreading in this figure is shown in both $p l$ anes of symmetry. The $Y_{0}, 5$ and $Z_{0} 5$ symbols shown in the figure are values of $Y$ and $Z$ at the local radial one-half plume velocities, or $U_{R}=0.5$ $U_{C}$. In the height dimension $(Z)$ of the two configurations, the plume spreading is only slightly less for the channel-type orifice than that for the sharp-edge orifice. In the width dimension (Y), large differences in the plume spreading are observed. The channel-type orifice spreading is generally much greater than that of the sharp-edge orifice, especially near the exit, due to the latter's vena contracta effect.

When the plume spreading of a channel-type orifice is compared with that of a nozzle (Ref. 19 data) much more similar plume spreading characteristics were obtained in both planes, as shown in Fig. 30. Althougin the aspect ratio of the two configurations is different, the shape of the plume spread curves with axial distance is similar. It should be noted that the height sides of the nozzle are parallel, as in the case of the channel-type orifice, while the width sides of the nozzle converge.

The axial undulation of the plume radial halfwidth curves (Fig. 30) are believed caused by one or both of the following factors: (1) the lack of sidewall convergence on all four sides of the nozzle, and (2) a contraction of the plume itself toward the nozzle centerline in the width dimension as the plume changes from a two-dimensional shape to an axisymmetric shape with increasing distance downstream from the nozzle exit. Further studies of these phenomena are needed.

In the following section, only nozzle and channel-type orifice data will be used to develop correlation parameters for plume spreading.

\section{Plume Spreading Correlation}

In Fig. 31, the cold-flow plume velocity spread in the height and width dimensions of twodimensional nozzles are shown in terms of the nozzle aspect ratio, equivalent diameter and $x\left(t_{j} / t_{a}\right) 0.25 / D_{e} \sqrt{1+M_{j}}$. Also shown in the figure is the plume spreading of a conic nozzle. 19 The two-dimensional nozzle height dimension ( $Z$ ) data show similar shapes to the conic nozzle curve, but are displaced by additional functions of aspect ratio. Correlation of the data, shown in Fig. 31 , was obtained by use of the following relationship: $\left[(z-b / 2) D_{e}\right] F_{z, b} \propto\left[x \sqrt{A R}\left(t_{j} / t_{a}\right)^{0.25} / 0_{e} \sqrt{1+M_{j}}\right] F_{z, x}$

where:

$$
F_{Z, b}=\left[1+0.25(A R-1)^{0.4}\right]
$$

and

$$
F_{z, X}=\left[1+0.000833(A R-1)^{3}\right]^{-1}
$$

The correlated data in the nozzle height dimension are shown in Fig. 32. The twodimensional data are generally in good agreement with the conic curve. In the plume core region near the nozzle exit some scatter is noted; however, this may be due to the small measurement differences, $Z-b / 2$, in the data rather than in the correlation method.

In Fig. 33 the cold flow plume velocity spread on the nozzle width dimension is shown together with that for a conic nozzle. A much greater variation in the $Y$-dimension data is seen to occur than that shown previously in the Zdimension. Not only are the data displaced as a function of the nozzle aspect ration but also as a function of a nozzle flare angle, B. Correlation of the data was obtained with the following relationship:

$\left[(y-\ell / 2) / 0_{e}\right] F_{y, \ell} \times\left[x\left(t_{j} / t_{a}\right)^{0.25} / D_{e} \sqrt{A R\left(1+M_{j}\right)}\right](1+\sin \beta)_{F, x}$

where:

$F_{y, l}=\left[\left\{1+2.67(A R-1)^{0.6}\{1+160(\sin B) 1.5\}\right]^{-1}\right.$

and

$F_{y, x}=\left[(1+0.367 \sqrt{A R}-1\}\left(1+4.25(\sin B)^{1.5}\right\}\right]^{-1}$

In general, the data in the Y-dimension of the nozzle are correlated by Eq. (10) as shown in Fig. 34. However, the undulations in the plume spreading curve discussed for Fig. 30 are not accounted for by Eq. (10) and show up in Fiq. 34 as deviations from the conic curve. The largest deviations occur for the channel-type orifice? with an aspect ratio of 10 . Lesser deviations occur with the nozzles having two convergent sides $\left(\right.$ data $\left.^{19}\right)$. The amount of deviation from the conic nozzle curve appears to be a complex function of the nozzle flare angle and aspect ratio. The least deviation from the conic nozzle curve was obtained with the nozzle having an aspect ratio of 6 and converging sides in the height dimension (data ${ }^{19}$ ). On the basis of the available limited data, it is recommended that the relationship expressed by Eq. (10) and Fig. 34 be used for estimating the plume spreading in the nozzle width dimension until additional data, particularly, with nozzles having all four sides converging, become available.

\section{Plume Spreading Angle}

The plume half-velocity spreading angle for a two-dimensional nozzle with an aspect ratio of 6 was briefly examined to determine the difference in the nozzle height and width spreading angles. Both the overall and local spreading angles were included in the evaluation. 
In Fig. 35 schematic sketches depicting the nomenclature used to define the overall, $\theta$, and local, $\theta^{\prime}$, spreading angles are shown. In Fig. 36, plume overall and local half-velocity spreading angles, based on data from Ref. 19, are shown. For comparison, spreading angles for a conic nozzle are also shown in this figure.

In Fig. 36(a) it is evident that the plume spreading angle in the nozzle height ( $Z$ ) dimension reaches a maximum nearly 3 times that in the nozzle width $(Y)$ dimension. Initially, the twodimensional nozzle spreading angle in both dimensions is larger than that of the conic nozzle. However, at $x / 0_{e}$ values $>12$, the spreading rate in the width dimension tends to level off and is less than

that of the conic nozzle. After an $x / D_{e}$ of 25 , the height dimension spreading angle decreases rapidly and approaches that of the conic nozzle at an $X / D_{e}$ of 40 .

In Fig. 36(b) the local plume half-velocity spreading angle in the height dimension increases rapidly with axial distance, reaching a maximum of about $7^{\circ}$ at an $x / 0 e_{0}$ of 23 ijefore decreasing rapidly to about $1.5^{\circ}$. The plume spreading angle in the width dimension shows a very erratic and oscillatory variation with $x / D_{e}$, with a maximum spreading angle of just over $3.5^{3}$ at an $\times / D_{e}$ of 35 . As a comparison, the conic nozzle local spreading angle increases continuously with $x / D_{e}$ and reaches a value of $4^{\circ}$ at an $x / D_{e}$ of 35 . The oscillatory nature of the local spreading angle in the width dimension is also evident in the overall spreading angle data ( $\mathrm{Fig} .36(\mathrm{a})$ ); however, in that case, the angle variation is less than $0.4^{\circ}$.

\section{Conclusions}

On the basis of the present correlation study concerned with two-dimensional plume decay and spreading characteristics, the following conclusions are made:

1. Two-dimensional plume centerline velocity and static temperature decay data were empirically correlated by suitable geometry and flow parameters that in their limits reduce to previously published single-stream correlations.

2. In the present correlation, the twodimensional plume centerline velocity and static temperature decay are analyzed in terms of three distinct regions previously identified in the literature, namely:

(a) An initial mixing region in which the flow is essentially asymmetric.

(b) A fully mixed region in which the flow is essentially axisymetric.

(c) A transition region between the initial and fully mixed regions.

3. The two-dimensional height and width spreading of the plume were correlated separately to the spreading characteristics of a conic nozzle because of their inherent different spreading characteristics in these two nozzle planes.
4. The two-dimensional plume variation of static temperature with velocity was similar to that for conic nozzles.

5. The correlations developed herein provide a means of estimating the plume centerline static temperature decay from cold-flow plume centerline velocity decay measurements.

\section{References}

1. von Glahn, U.H., "On Some Flow Characteristics of Conventional and Excited Jets," AIAA Paper 84-0532, Jan. 1984.

2. von Glahn, U.H., Goodykoontz, J., and Wasserbauer, $C_{.}$: "Velocity and Temperature Characteristics of Two-Stream, Coplanar Jet Exhaust Plumes," AIAA Paper 84-2205, Aug. 1984 .

3. von Glahn, U.H., Goodykoontz, 3., and Wasserbauer, C.: "Velocity and Temperature Decay Characteristics of Inverted-Profile Jets," AIAA Paper 86-0312, Jan. 1986.

4. Sforza, P.M., Steiger, M.H., and Trentacoste, N., "Studies on Three-Dimensional Viscous Jets," AIAA Journal, Vol. 4, No. 5, May 1966, pp. 800-806.

5. Trentacoste, N., and Sforza, P.: "Further Experimental Results for Three-0imensional Free Jets," AIAA Journal, Vol. 5, No. 5, May 1967, pp. 885-891.

6. Sforza, P., "A Quasi-Axisymmetric Approximation for Turbulent, Three-Dimensional Jets and Wakes," AlAA Journal, Vol. 7, No. 7, July 1969, pp. 1380-1383.

7. Sfeir, A.A., "The Velocity and Temnerature Fields of Rectangular Jets," International Journal of Heat and Mass Transfer, Vol. 19, No. 11, Nov. 1976, pp. 1289-1297

8. Sforza, P.M., and Stasi, W., "Heated ThreeDimensional Turbulent Jets," ASME 77-WA/HT-27, Dec. 1977.

9. Sfeir, A.A., "Investigation of ThreeDimensional Turbulent Rectangular Jets," AIAA Journal, Vol. 17, No. 10, Oct. 1979, pp. $1055-1060$

10. Sato, H., "The Stability and Transition of a Two-Dimensional Jet," Journal of Fluid Mechanics, Vol. 7, Part 1, Jan. 1960, pp. 53-80.

11. Jiji, L.M., and Moghadam, S.M., "Theoretical and Experimental Investigation of ThreeDimensional Buoyant Turbulent Jets," Heat Transfer 1982, Vol. 2, U. Grigull, E. Hahne, K. Stephan and J. Straub, Eds., Hemisphere Publishing, New York, 1982, pp. 425-430.

12. Weinstein, A.S., Osterle, J.F., and Forstal1, W., "Momentum Diffusion From a Slot Jet Into a Moving Secondary," Journal of Applied Mechanics, Vol. 23, No. 3, Sept. 1956, pp. 437-443. 
13. Chambers, F.W., and Goldschmidt, V.W., "Acoustic Interaction With a Turbulent Plane Jet - Effects on Mean Flow, "AIAA Paper 81-0057, Jan. 1981.

14. Goldschmidt, V.W., and Kaiser, K.F., "Interaction of an Acoustic Field and a Turbulent Plane Jet: Mean Flow Measurements," AIChE Chemical Engineering Progress Symposium Series, Vo1. 67, №. 109, 1971, pp. 91-98.

15. Thomas, F.0., and Goldschmidt, V.W.: "Interaction of an Acoustic Disturbance and a TwoDimensional Turbulent Jet: Experimental Data," Journal of Fluids Engineering, Vol. 105, No. 2, June 1983, pp. 134-139.

16. Krothapalli, A., Baqanoff, D., and Karamcheti, K.; "Basic Studies of Multiple Free and Conf ined Jets," AFOSR TR-84-1176, 1984.

17. Groesbeck, D.E., Huff, R.G., and von Glahn, U.H.: "Comparison of Jet Mach Number Decay Data With a Correlation and Jet Spreading Contours for a Lai $y \in$ Variety of Nozzles," NASA TN D-8423, 1977.
18. Higgins, C.C., Kelly, D.P., and Wainwright, T.W., "Exhaust Jet Wake and Thrust Characteristics of Several Nozzles Designed for VTOL Downwash Suppression," NASA CR-373, 1966.

19. Higgins, C.C., and Wainwright, T.W., "Dynamic Pressure and Thrust Characteristics of Cold Jets Discharging from Several Exhaust Nozzles Designed for VTOL Downwash Suppression," NASA TN D-2263, 1964.

20. Rockwe11, D., "External Excitation of Planar Jet," Journal of Applied Mechanics, Vol. 39, No. 4, Dec. 1972, pp. 883-890.

21. Balsa, T. et al.: "High Velocity Jet Noise Source Location and Reduction: Task 2Theoretical Developments and Basic Experiments," FAA Report No. FAA-RD-76-79, II, May 1978.

22. Förthmann, E., "Turbulent Jet Expansion," NACA TM-789, 1934.

23. Davies, A.E., Keffer, J.F., and Baines, W.D., "Spread of a Heated Plane Turbulent Jet," Physics of Fluids, Vol. 18, No. 7, July 1975, pp. 770-775. 


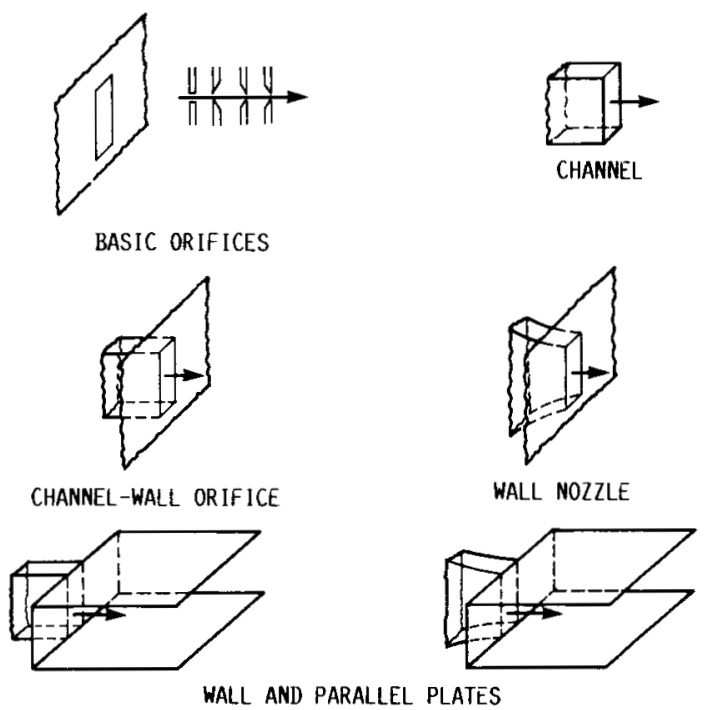

FIGURE 1. - SCHEMATIC SKETCHES OF VARIOUS ORIFICE/WALL CONFIGURATIONS REPORTED ON IN THE LITERATURE.

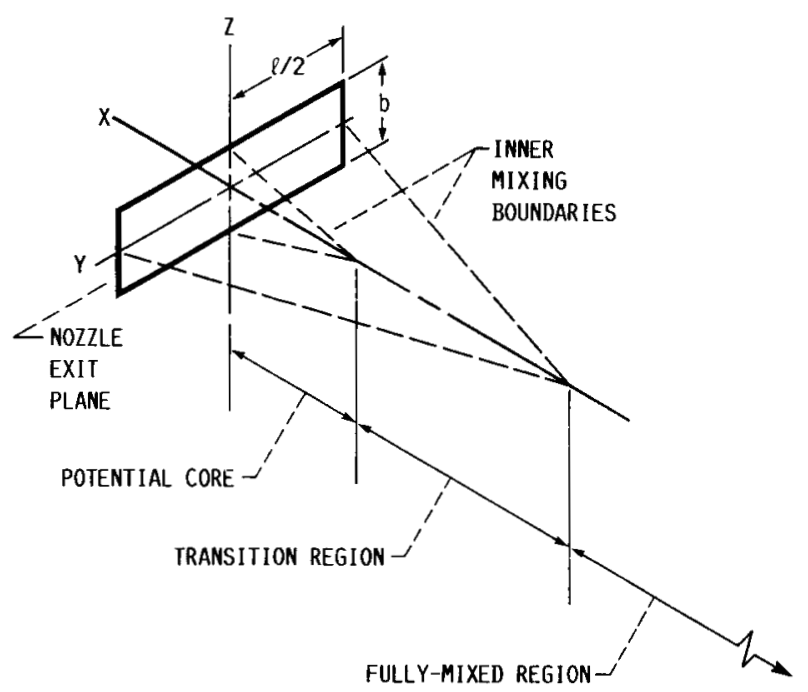

FIGURE 2. - SCHEMATIC SKETCH OF TWO-DIMENSIONAL ORIFICE/NOZZLE PLUME REGIONS.
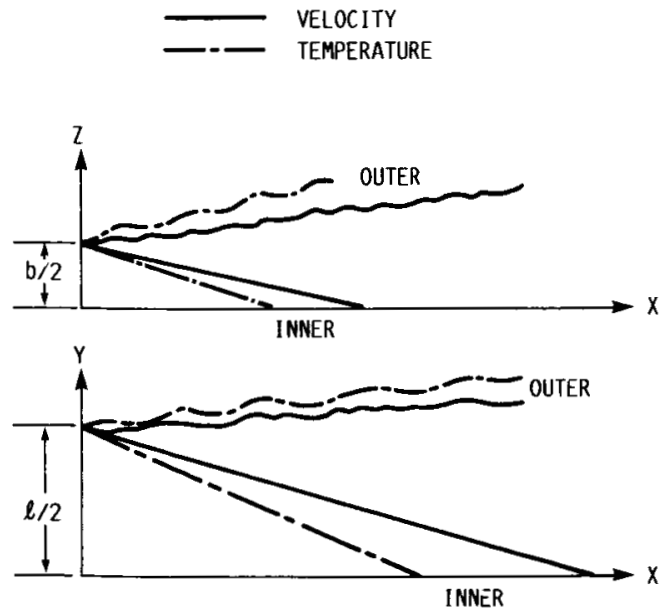

FIgURE 3. - SCHEMATIC SKEICH OF INNER AND OUTER PLUME MIXING REGIONS.

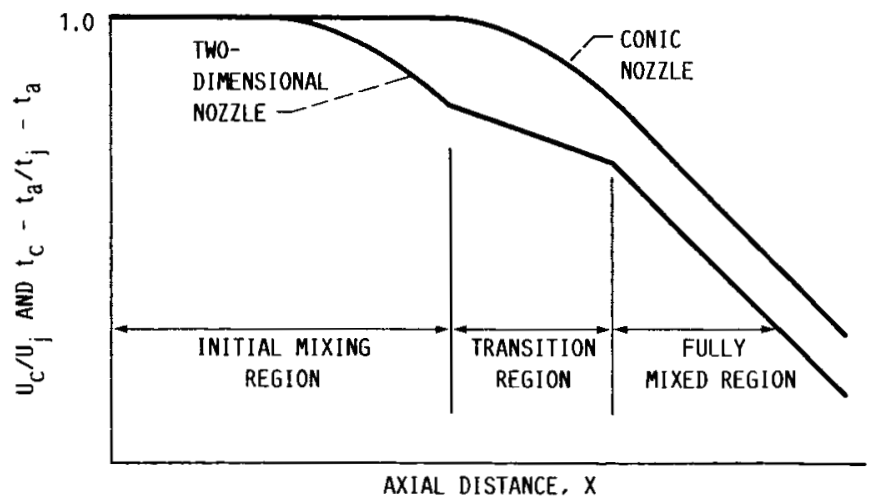

FIGURE 4. - SCHEMATIC SKETCH OF TWO-DIMENSIONAL NOZZLE PLUME CENTERLINE VELOCITY AND STATIC TEMPERATURE. DECAY. 


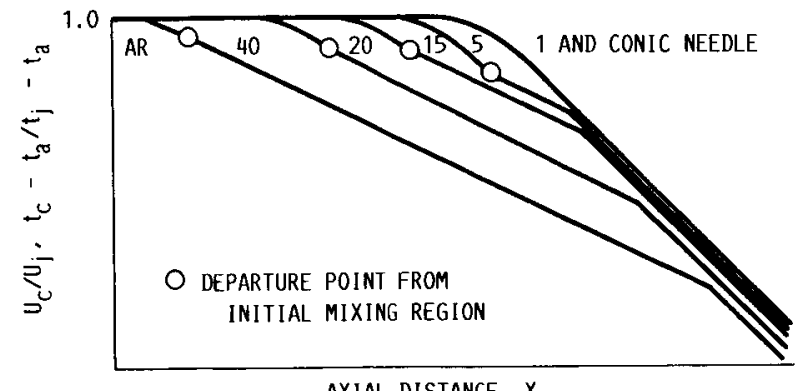

AXIAL DISTANCE, $X$

FIGURE 5. - SCHEMATIC SKETCH OF THE EFFECT OF TWO-DIMENSIONAL NOZZLE ASPECT RATIO ON THE PLUME CENTERLINE VELOCITY AND TEMFERATURE DECAY.

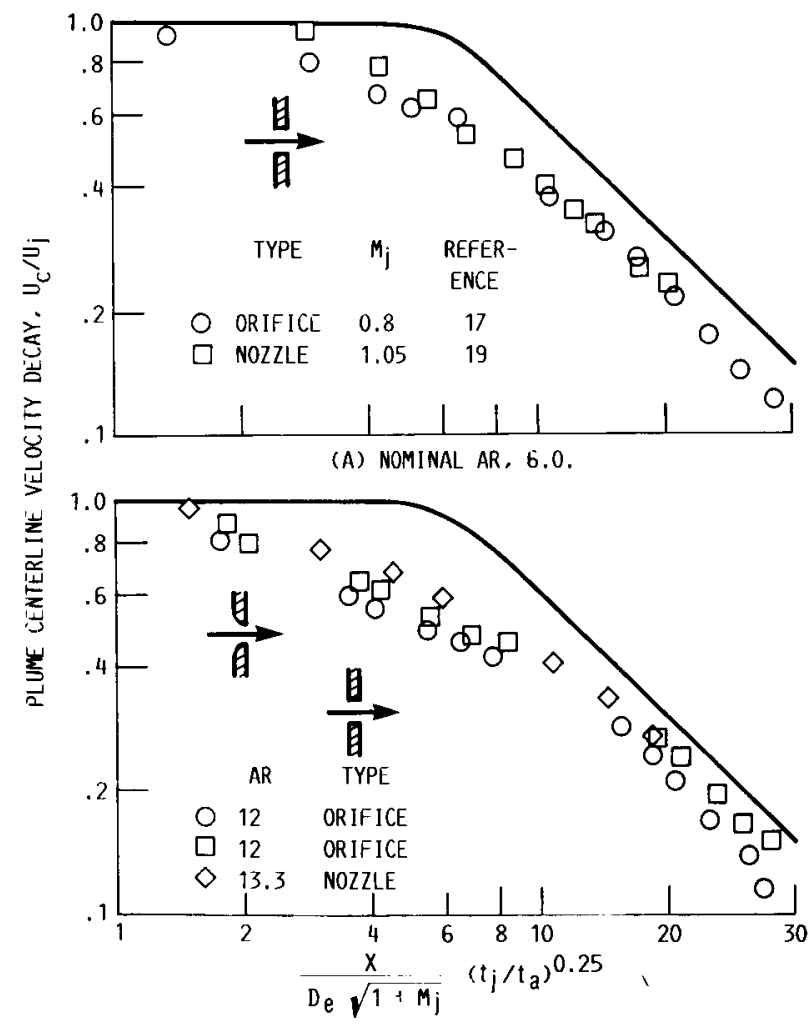

(B) NOMINAL AR, $12.0 ;$ REFERENCE $17 ; M_{j}, 0.8$.

FIGURE 7. - COMPARISON OF PLUME CENTERLINE VELOCITY DECAY FOR VARIOUS TWO-DIMENSIONAL ORIFICES AND NOZZLES. COLD FLOW.
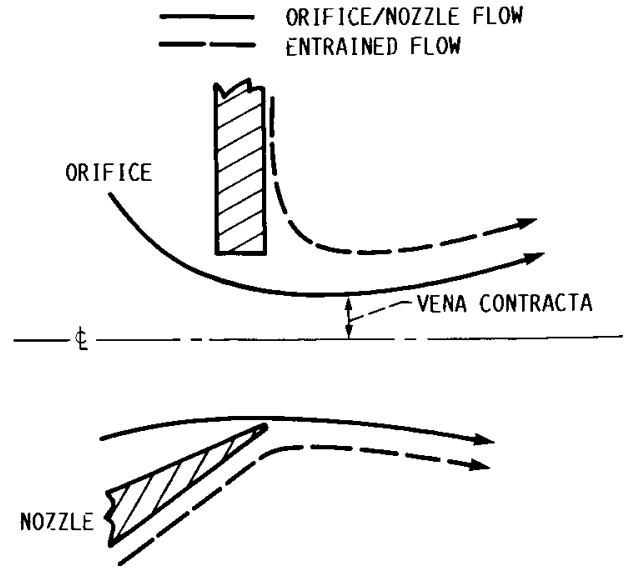

FIGURE 6. - SCHEMATIC SKETCH SHOWING GROSS DIFFERENCES BETWEEN ORIFICE AND NOZZLE PLUME STREAMLINES.

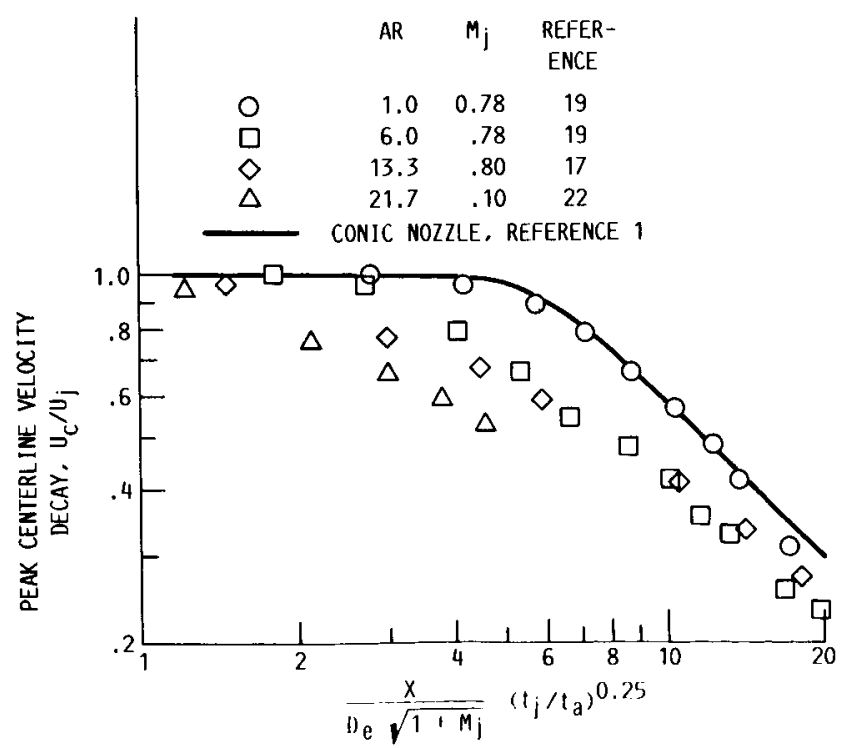

FIGURE 8, - EFFECT OF NOZIII.E. ASPECT RATIO, AR, ON THE PEAK CENTERLINE VEL OCITY DECAY OF TWO-DIMENSIONAL. NOZZLES. COLD FLOW. 


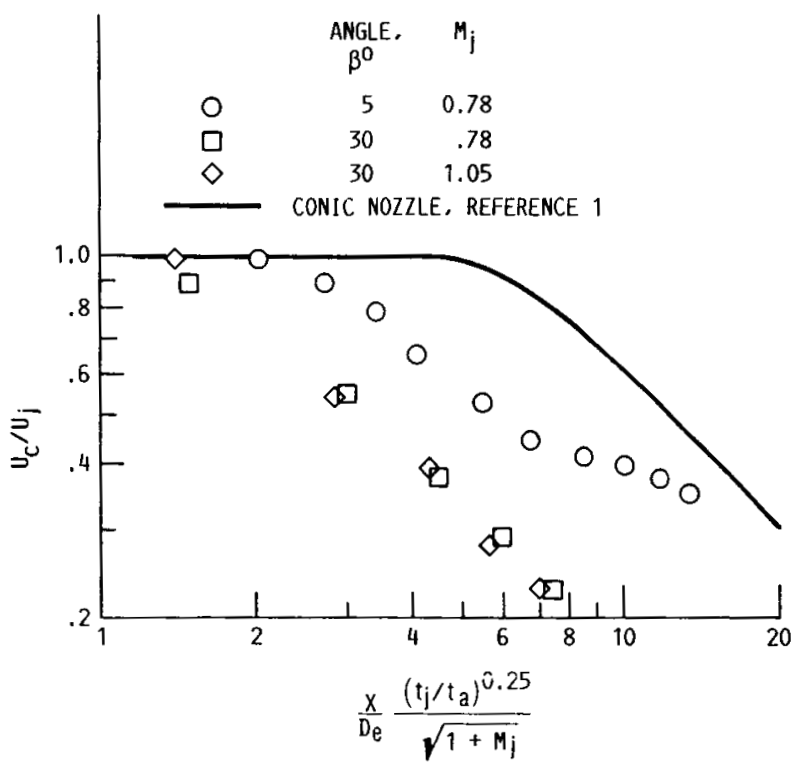

FIGURE 9. - EFFECT OF FLARE ANGLE (DELTA NOZZLE) ON PLUME CENTERLINE VEL OCITY DECAY. REFERENCE 19; COLD FLOW.

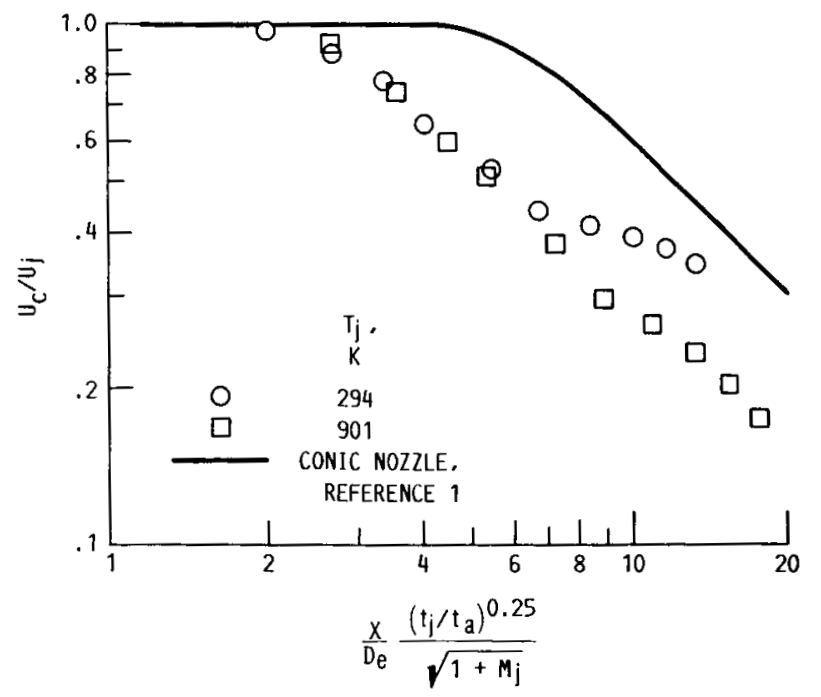

FIgURE 11. - EFFECT OF JET TEMPERATURE ON DELTA NOZZLE CENTERLINE VELOCITY DECAY. $M_{j}, 1.07 ; \beta, 5^{\circ}$, REFERENCE 18.

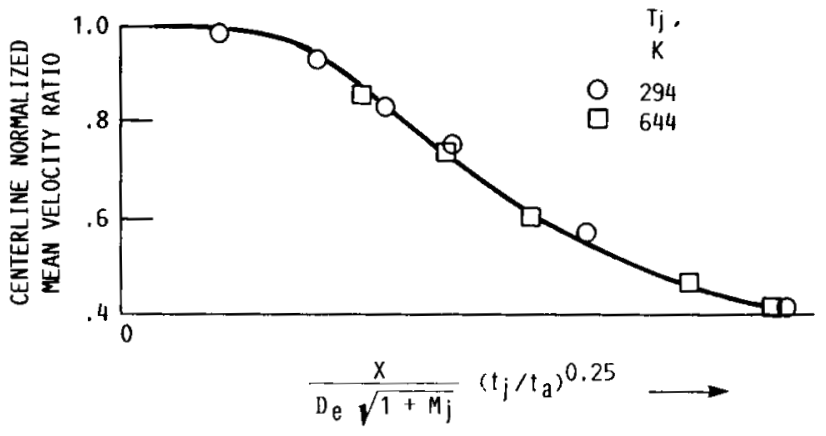

FIGURE 10. - PLIMME CENTERLINE VELOCITY DECAY FOR THODIMENSIONAL NOZZLE OF AR $=5 . M, 0.967$; REFERENCE 21

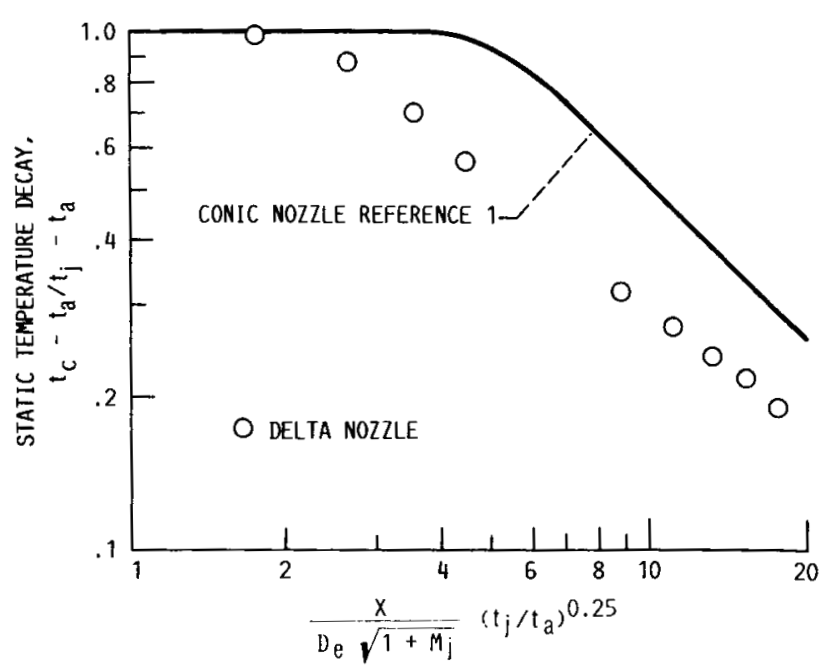

FIGURE 12. - PLUME CENTERLINE STATIC STATIC TEMPERATURE DECAY FOR A DELTA NOZZLE OF AR $=5$ AND $\beta=5^{\circ} \mathrm{T}_{j}, 901 \mathrm{~K}$; REFERENCE 18. 


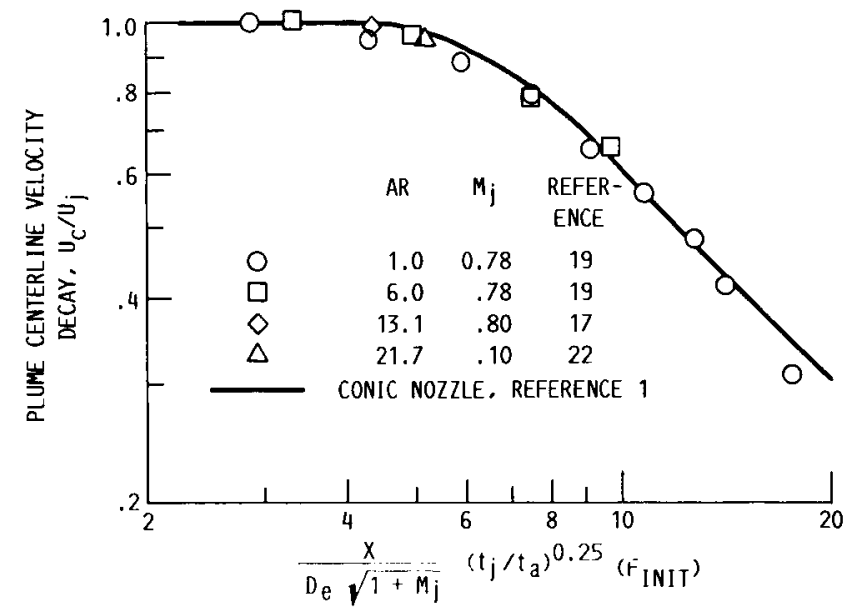

FiguRE 13. - CORRELATED PluME CENTERL INE VELOCITY DECAY IN THE. INITIAL MIXING REGION OF TWO-DIMENSIONAL NOZZLES. COLD FLOW

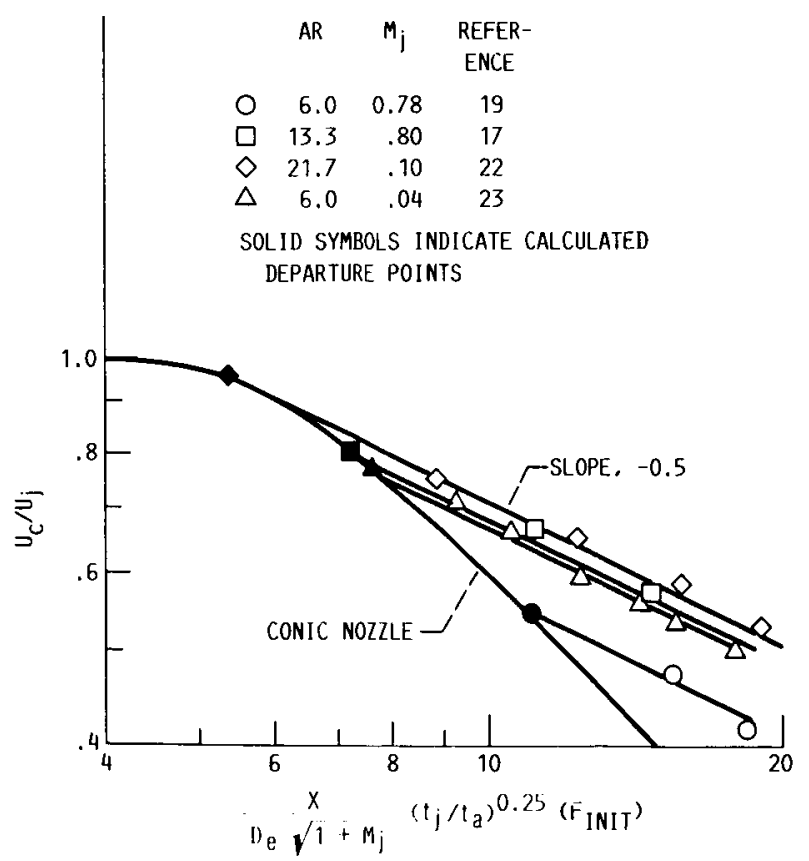

FIGURE 15. - CORRELATION OF PLUME CENTERLINE VELOCITY DECAY DATA IN THE TRANSITION REGION OF TWO-DIMENSIONAL NOZZLES. COLD FLOW.

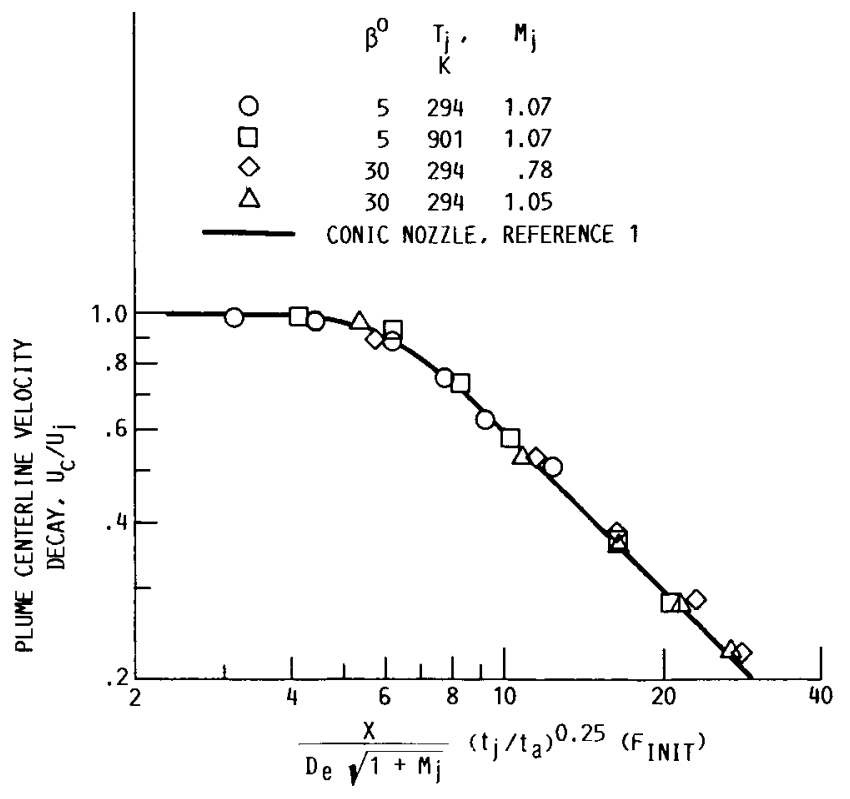

FIGURE 14. - CORRELATED PLUME CENTERLINE VELOCITY DECAY IN THE INITIAL MIXING REGION OF TWO-DIMENSIONAL DELTA NOZZLES. REFERENCE 18 DATA.

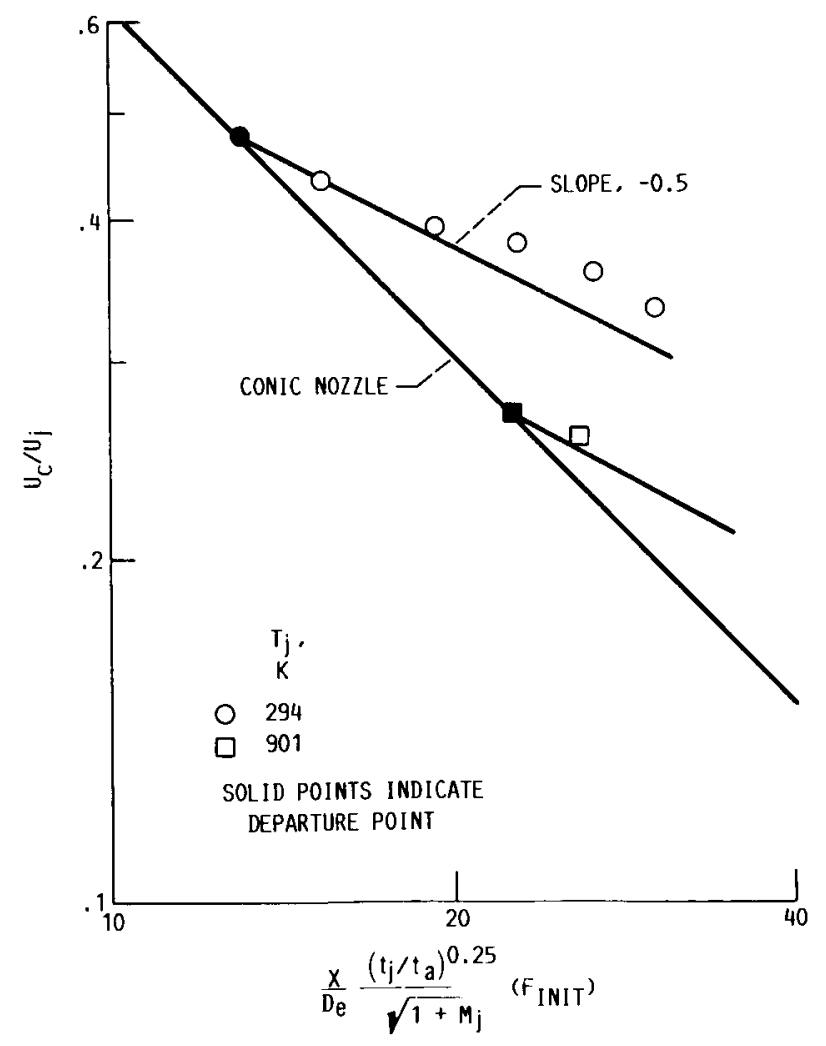

FIGURE 16. - CORRELATION OF PLUME CENTERLINE VELOCITY DECAY DATA IN THE TRANSIIION REGION OF TWO-DIMENSIONAL DELTA NOZZLES. $\beta, 5^{0} ; M_{j}, 1.07$; REFERENCE 18. 


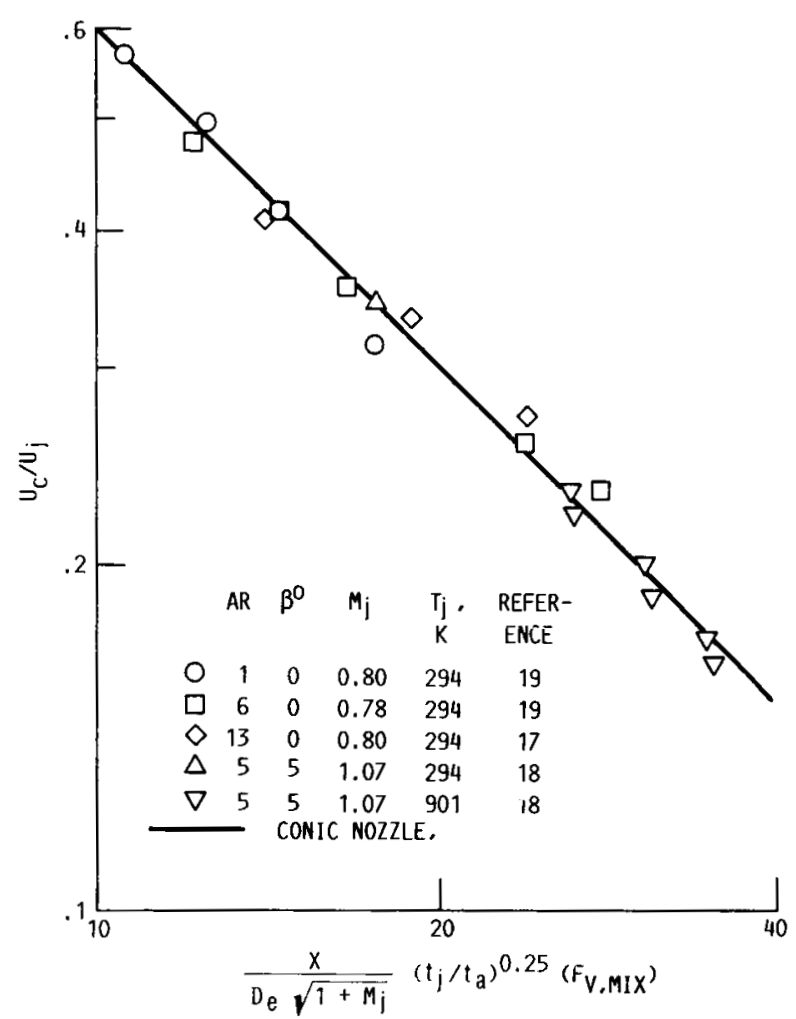

FIGURE 17. - CORRELATION OF PLUME CENTERLINE VELOCITY DECAY DATA IN FULLY-MIXED REGION FOR UNFLARED AND FLARED TWO-DIMENSIONAL NOZZLES.

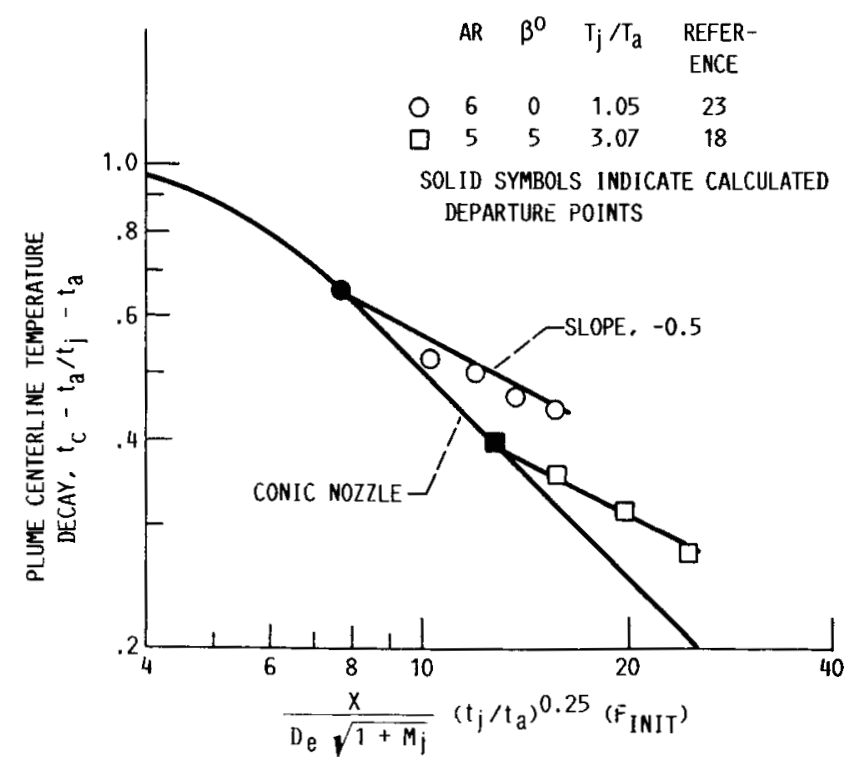

FIGURE 19. - CORRELATED PLUME CENTERLINE TEMPERATURE DECAY IN TRANSITION REGION OF TWO-DIMENSIONAL NOZZLES.

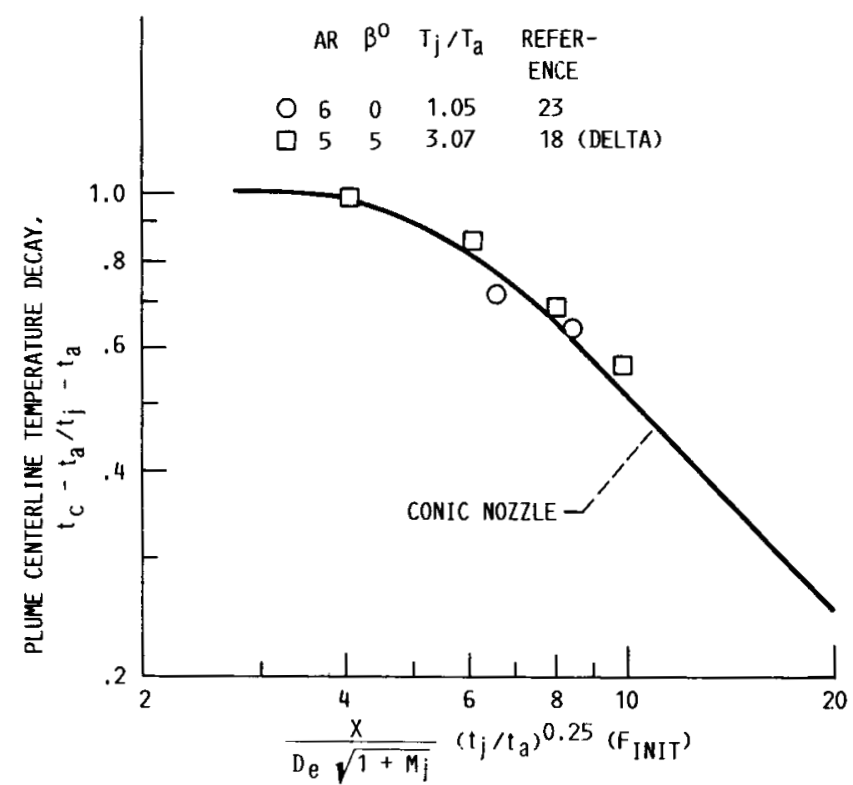

FIGURE 18. - CORRELATED PLUME CENTERLINE TEMPERATURE DECAY IN INITIAL MIXING REGION OF TWO-DIMENSIONAL NOZZLES.

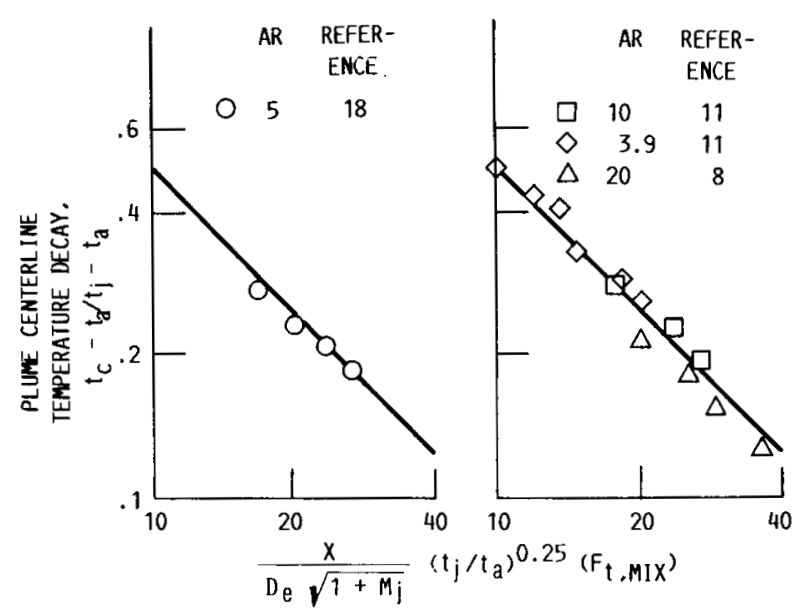

$\begin{array}{ll}\text { (A) DELTA NOZZLE: } M_{j}, & \text { (B) SHARP-EDGE ORIFICES: }\end{array}$ 1.07: $\mathrm{T}_{\mathrm{j}} / \mathrm{T}_{\mathrm{a}} \cdot 3.07 . \quad \mathrm{M}_{\mathrm{j}},<0.1: \mathrm{T}_{\mathrm{j}} / \mathrm{T}_{\mathrm{a}} \cdot \sim 1.05$. FIGURE 20. - CORRELATED PL UME CENTERLINE TEMPERATURE DECAY IN FULLY-MIXED REGION OF A TWO-DIMENSIONAL NOZZLE AND SEVERAL ORIFICES. 


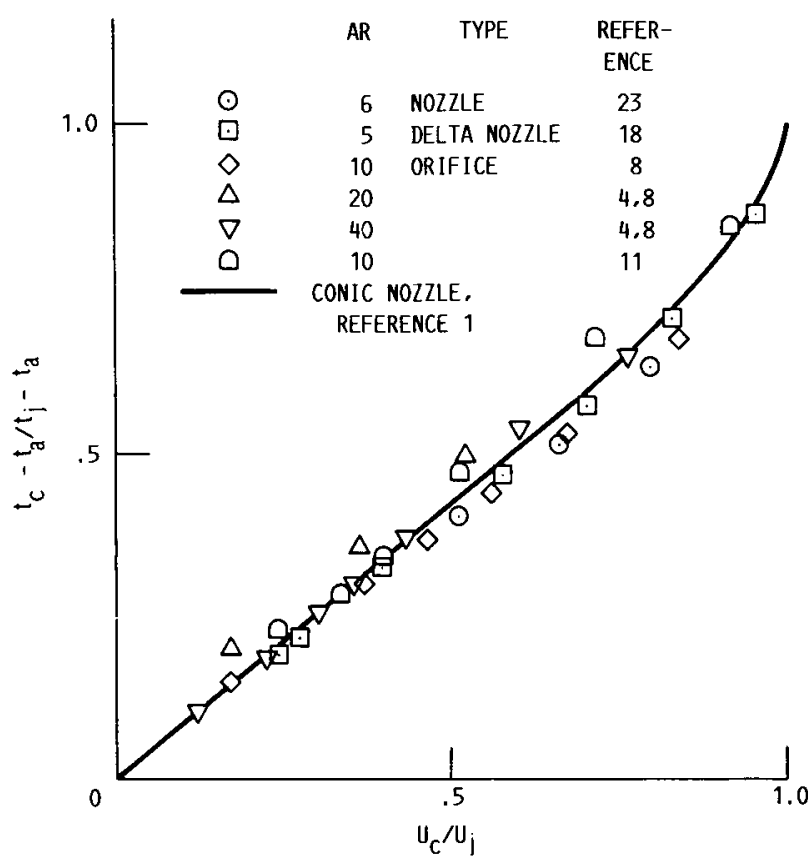

FIGURE 21. - TYPICAL VARIATION OF LOCAL PLUME CENIERLINE TEMPERATURE RATIO WITH LOCAL VELOCITY RATIO FOR TWO-DIMENSIONAL NOZZLES AND ORIFICES.
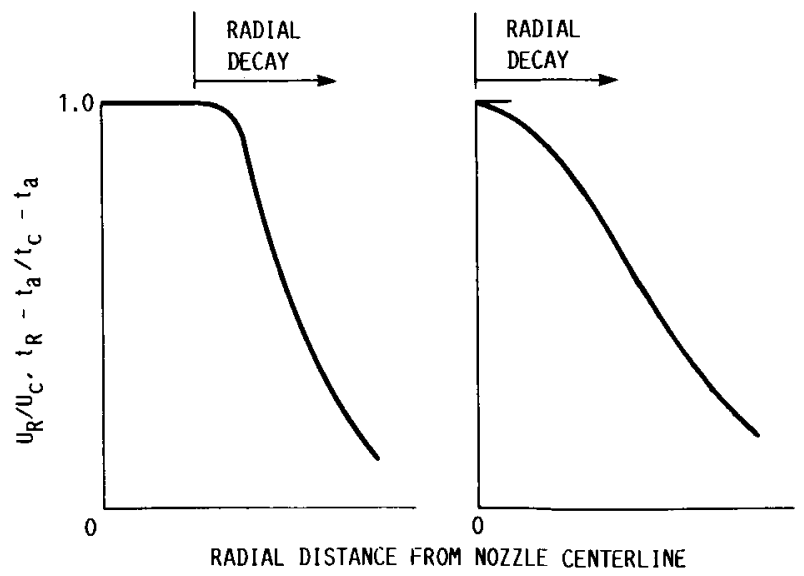

(A) CORE REGIONS.

(B) DOWNSTREAM OF CORE REGIONS.

FigURE 22. - SCHEMATIC REPRESENTATION OF PLUME RADIAL DECAY PROFILES IN NOZZLE WIDTH ( $Y$ ) AND HEIGHT (Z) DIRECTIONS. 


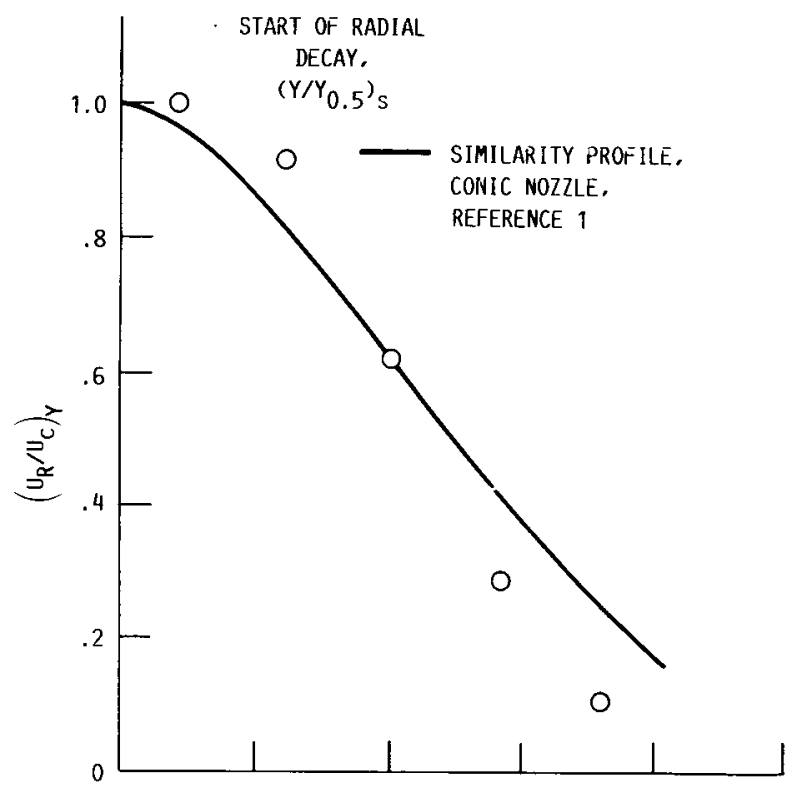

(A) NOZZLE AR, $6 ; M_{j}, 0.78 ;$ REFERENCE $19 ; \mathrm{X} / \mathrm{D}_{\mathrm{e}}, 2$; COLD FLOW.

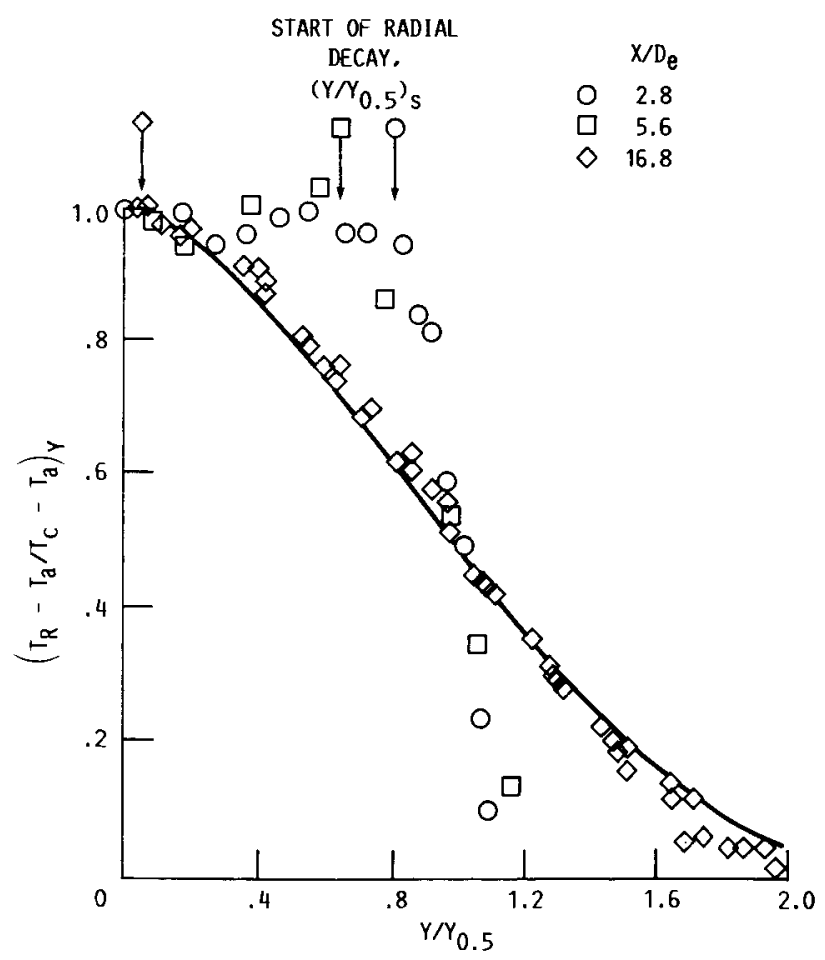

(B) ORIFICE AR, 40; $T_{j}, 373 \mathrm{~K}$; REFERENCE 8.

FIGURE 23. - REPRESENTATIVE RADIAL VELOCITY AND TEMPERATURE DECAY DATA IN WIDTH DIMENSION (Y) OF TWO-DIMENSIONAL CORE REGION.
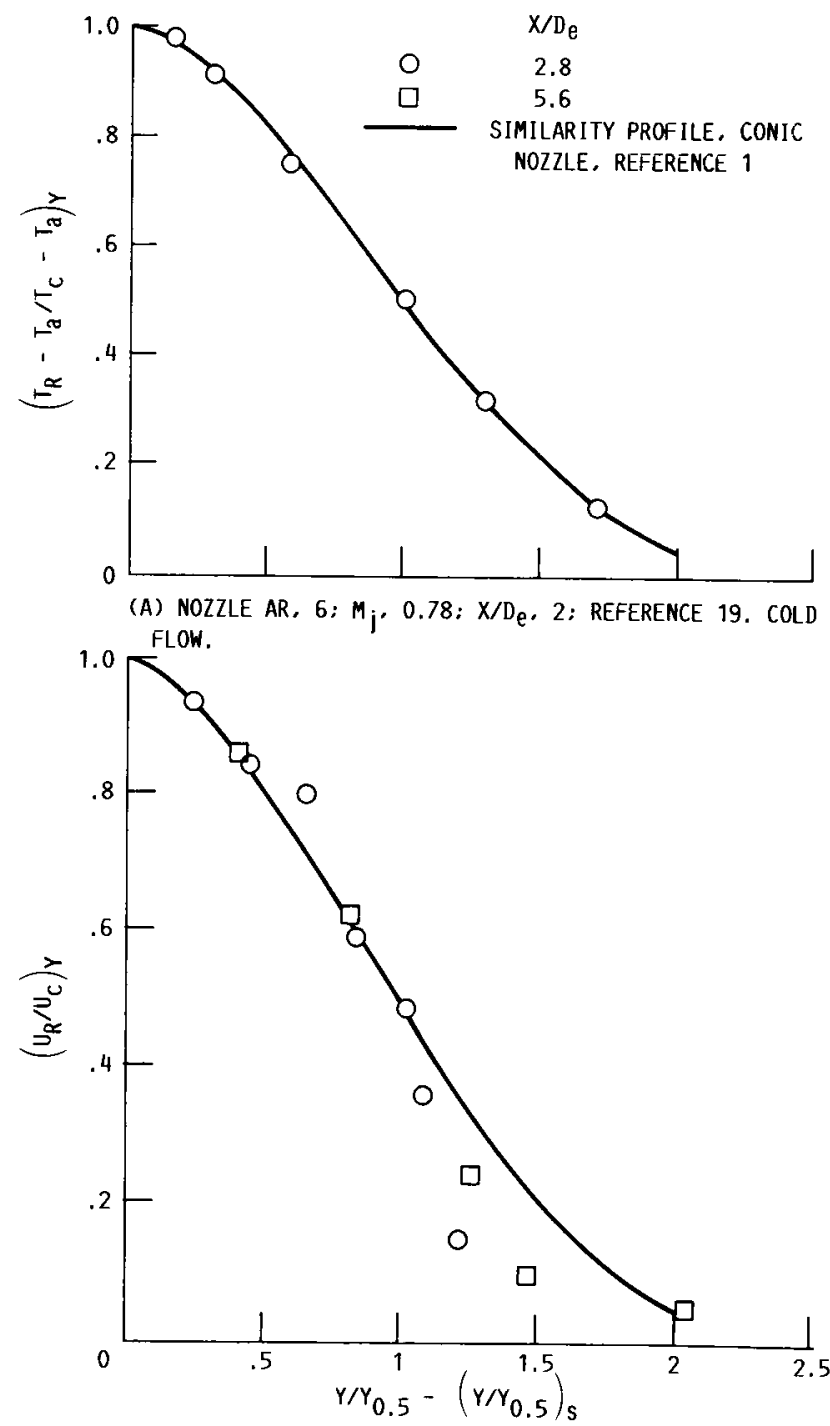

(B) ORIFICE AR, 40; $T_{j}, 373 \mathrm{~K}$ : REFERENCE 8. FIGURE 24. - CORRELATED RADIAL VELOCITY AND TEMPERATURE DECAY DATA IN WIDTH DIMENSION (Y) OF TWO-DIMENSIONAL CORE REGION. 


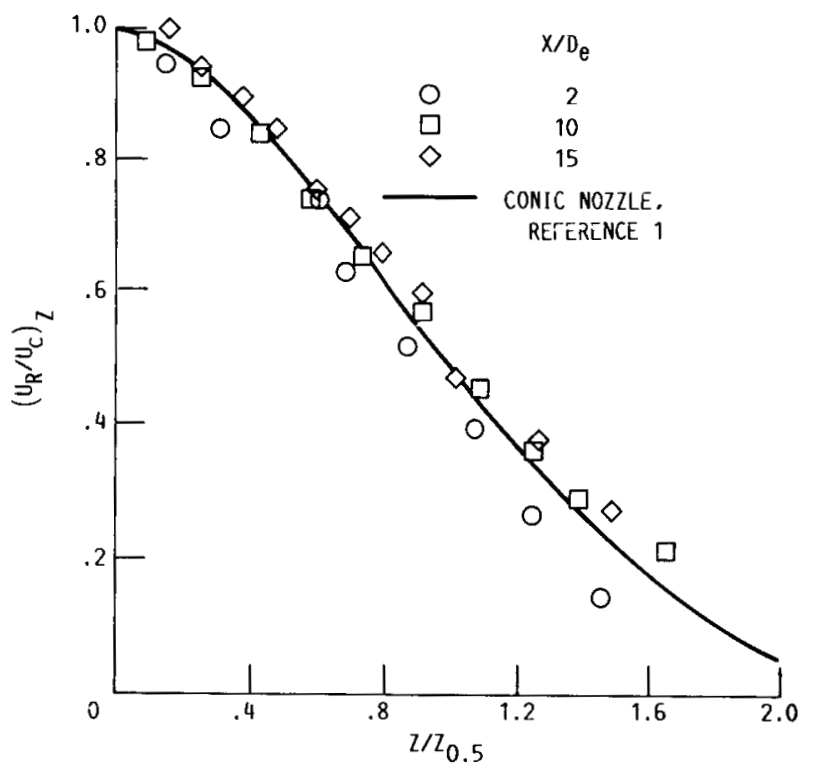

(A) NOZZLE. HEIGHT, 2 .

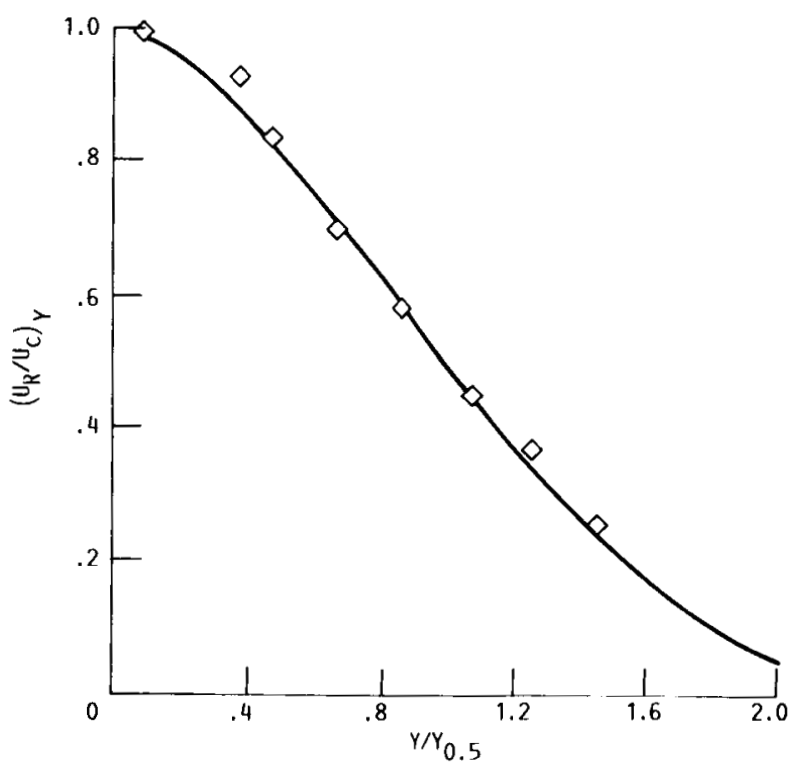

(B) NOZZLE WIDTH, Y.

FIGIIRE 25. - RADIAL VELOCITY DECAY IN PLUME TRANSITION FLOW REGION OF A TWO-DIMENSIONAL NOZZLE. AR, 6: $M_{j} \cdot 0.78$; COLD FLOW; REFERENCE 19 DATA.
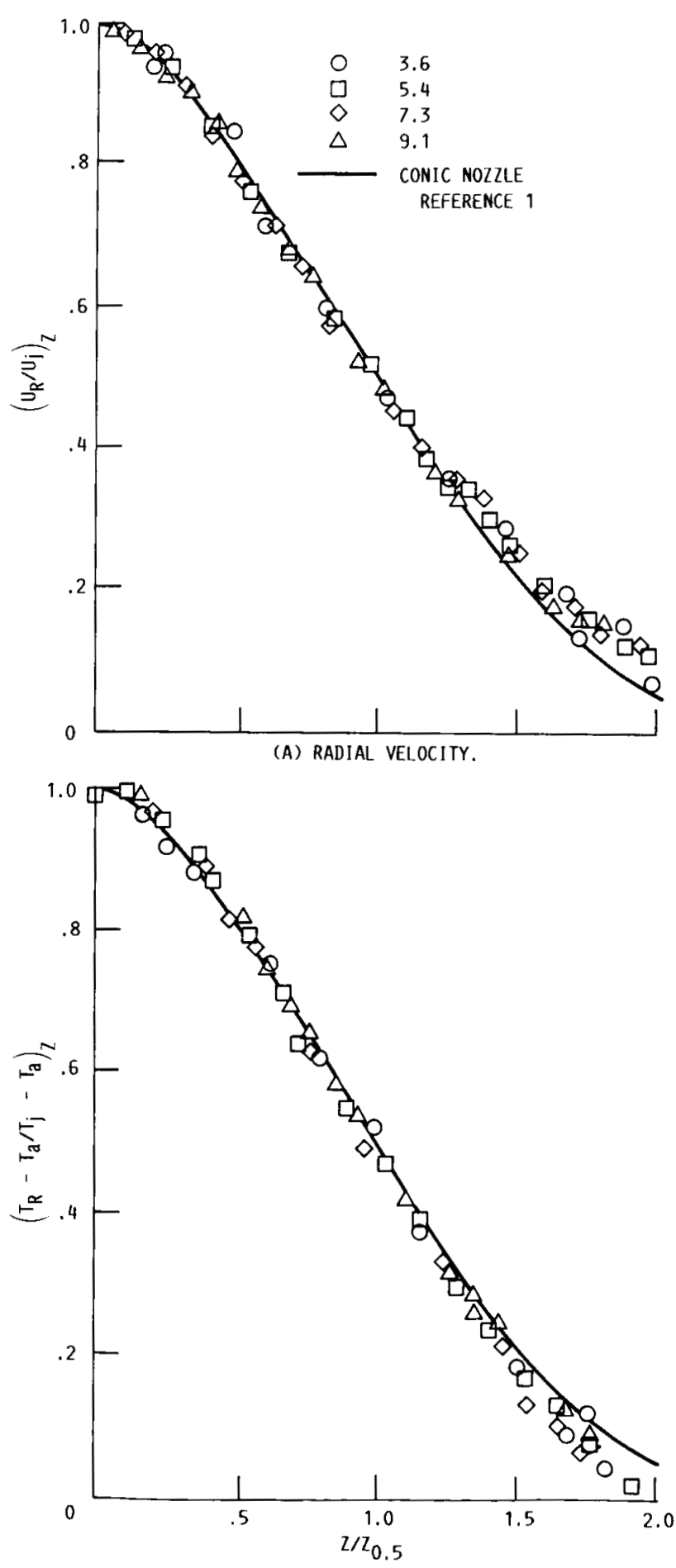

(B) RADIAL TEMPERATURE.

FIGURE 26. - RADIAL VELOCITY AND TEMPERATURE PROFILES OF A TWO-DIMENSIONAL NOZZLE. REFERENCE $23: U_{j} \cdot 13.5 \mathrm{~m} / \mathrm{s}$; $\mathrm{T}_{\mathrm{j}}-\mathrm{T}_{\mathrm{a}} \cdot 14.6 \mathrm{~K} ; \mathrm{AR}, 6$. 


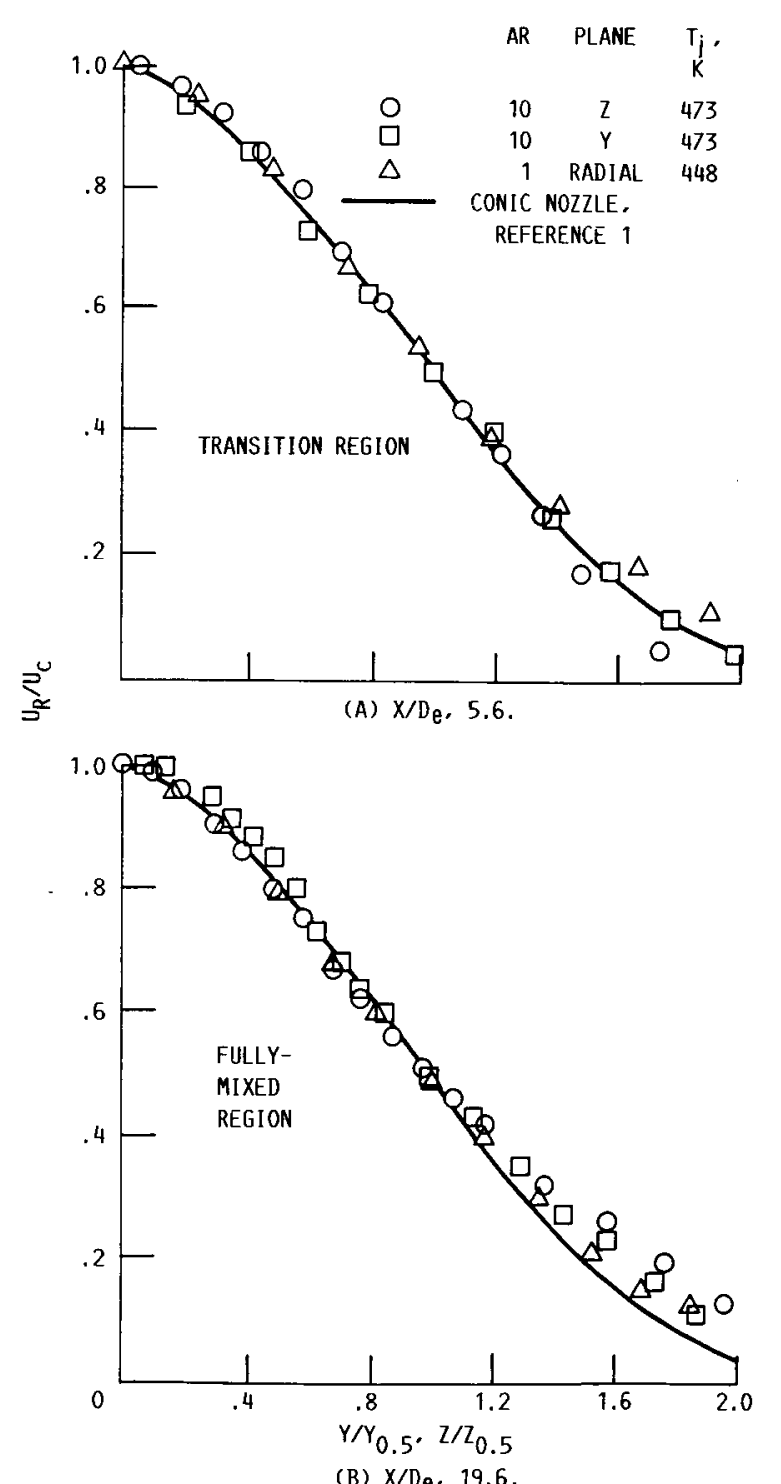

(B) $X / D_{\mathrm{e}}, 19.6$.

FIGURE 27. - RADIAL VELOCITY AND TEMPERATURE PROFILES OF A THO-DIMENSIONAL ORIFICE. REFERENCE 8; AR, 6.

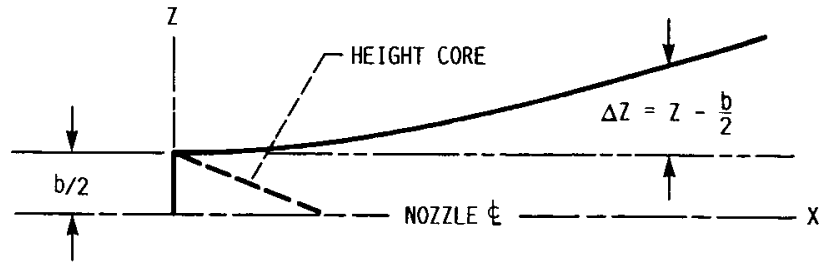

(A) NOZZLE HEIGHT DIRECTION.

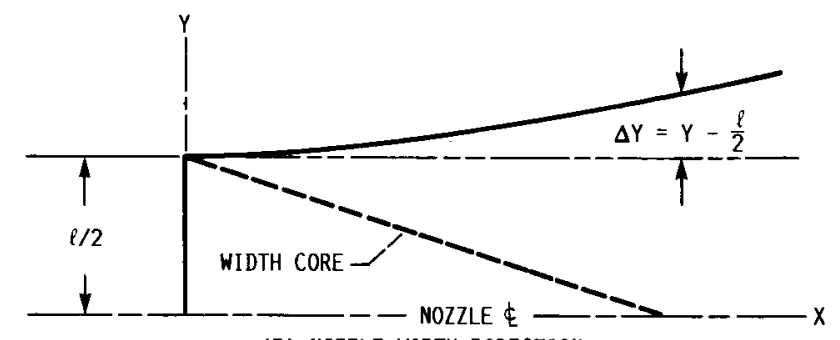

(B) NOZZLE WIDTH DIRECTION.

FIGURE 28. - SCHEMATIC SKETCH ILLUSTRATING RADIAL SPREADING DIMENSIONS FOR THE LOCAL HALF-VELOCITY, $\mathrm{v}_{\mathrm{c}} / 2$.

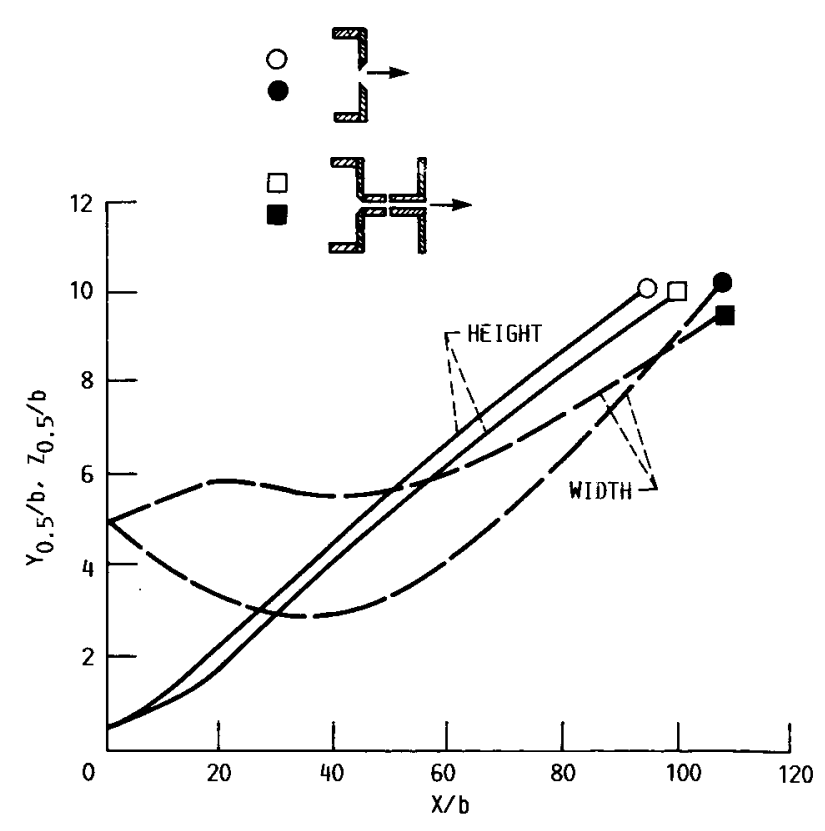

FIGURE 29, - EFFECT OF ORIFICE TYPE ON JET SPREAD. Re, $12200:$ b. $0.4 \mathrm{cM} ;$ l. $4 \mathrm{cM} ; D_{e}, 1.427 \mathrm{cM} ; A R, 10$; REFERENCE 5 . 


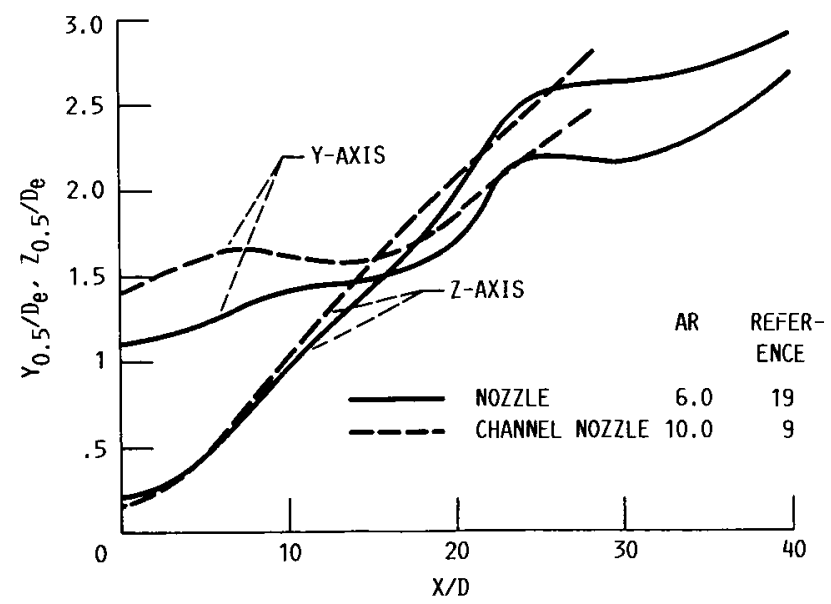

FIGURE 30. - COMPARISON OF PI IMME SPREADING CHARACTERISTICS FOR A CHANNEL-TYPE ORIFICE AND A TWO-DIMENSIONAL NOZZLE.

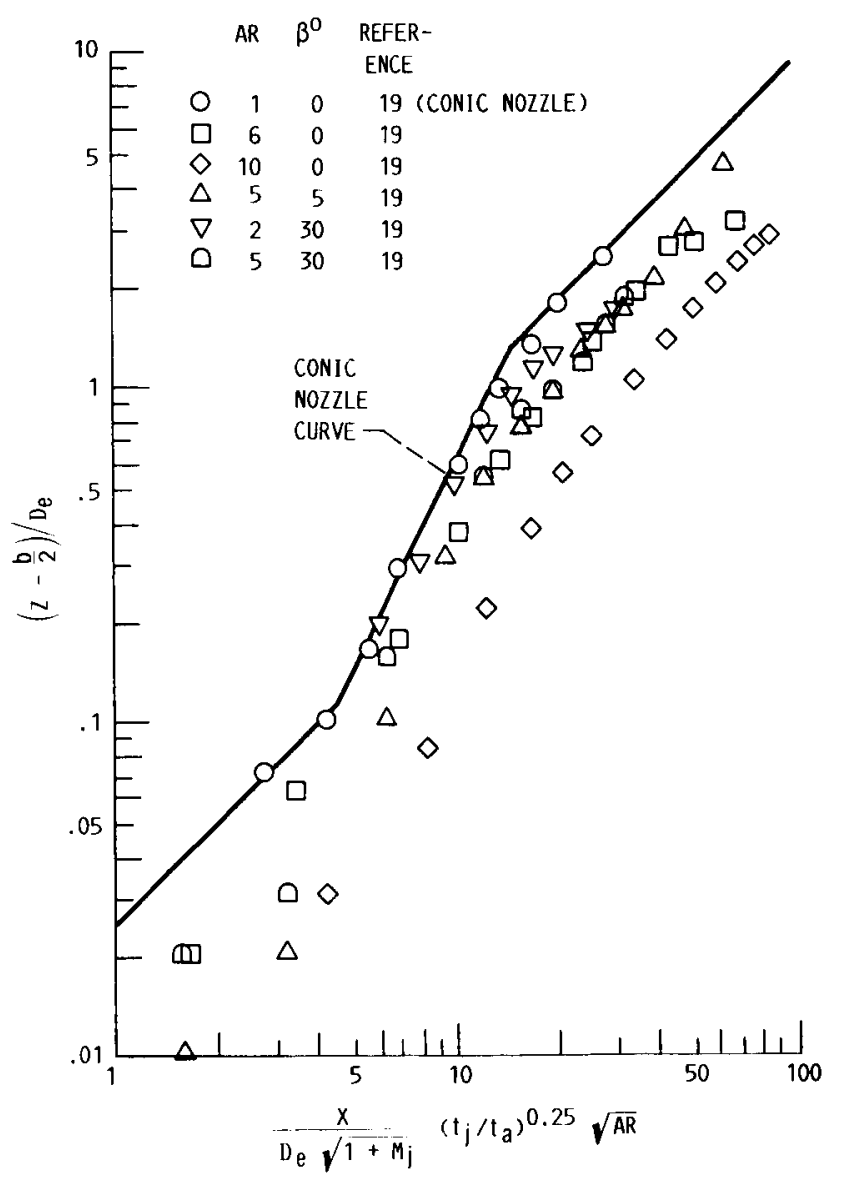

FIGURE 31. - LOCAL PLUME HALF-VELOCITY $\left(U_{C} / 2\right)$ VARIATION IN MOZZLE HEIGHT ( $Z$ ) DIMENSION AS A FUNCTION OF AXIAL EXIT PLANE.

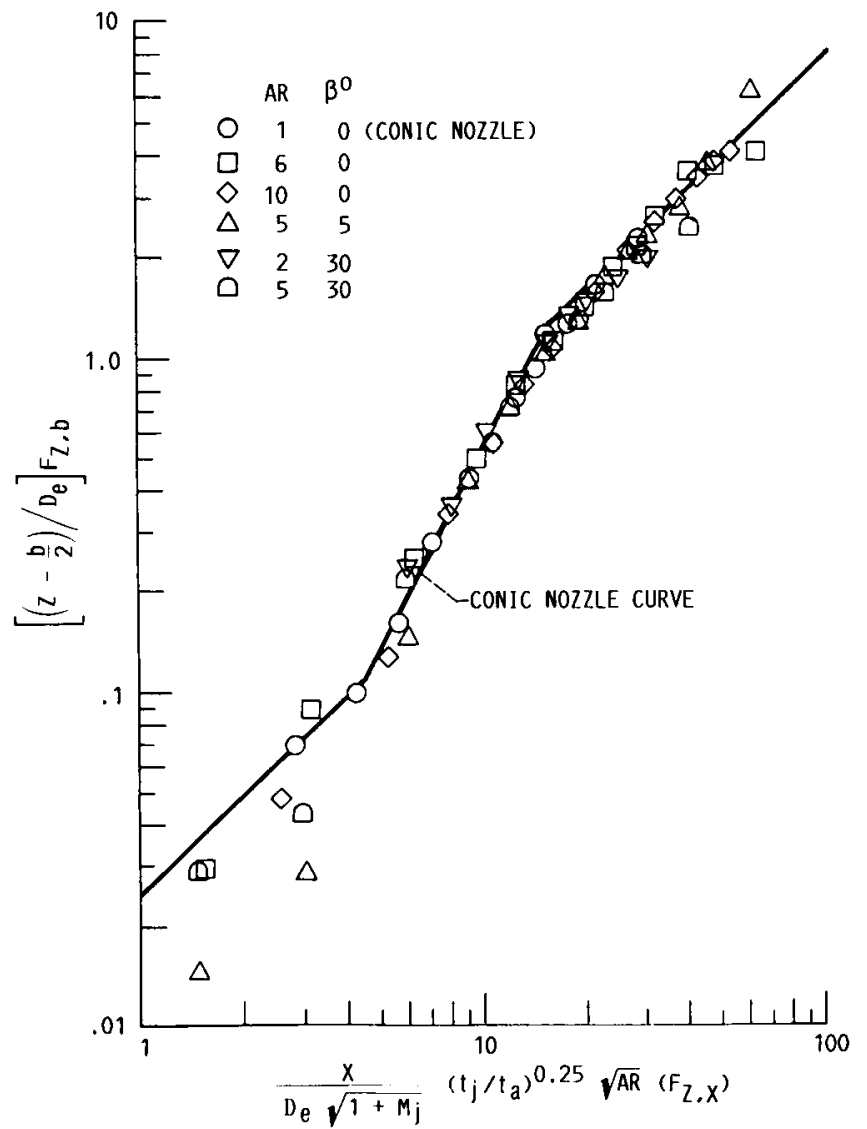

FIgURE 32. - CORRELATED LOCAL PLUME HALF-VELOCITY $\left(U_{C} / 2\right)$ IN NOZZLE HEIGHT (Z) DIMENSION. 


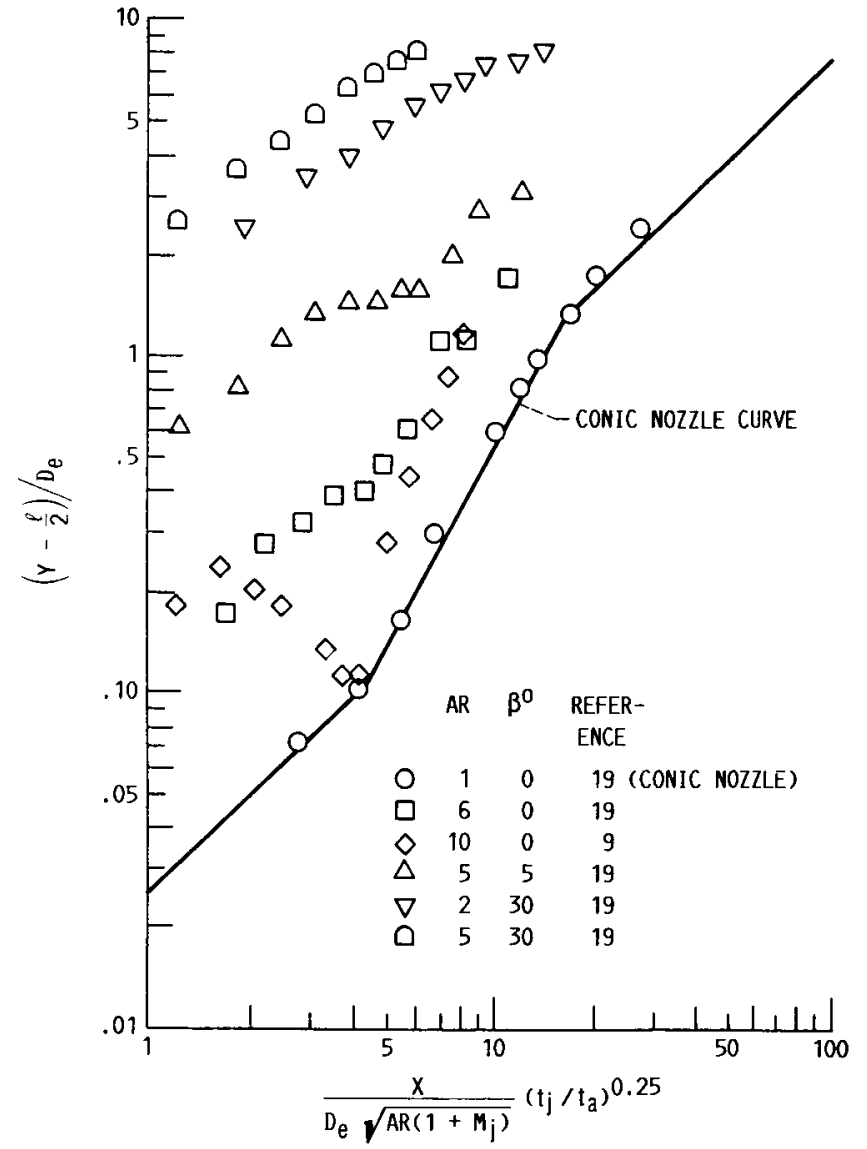

FIGURE 33. - LOCAL PLUME HALF-VELOCITY (U $/ 2)$ VARIATION IN NOZZLE WIDTH (Y) DIMENSION AS A FUNCTION OF AXIAL DISTANCE FROM NOZZLE EXIT PLANE.

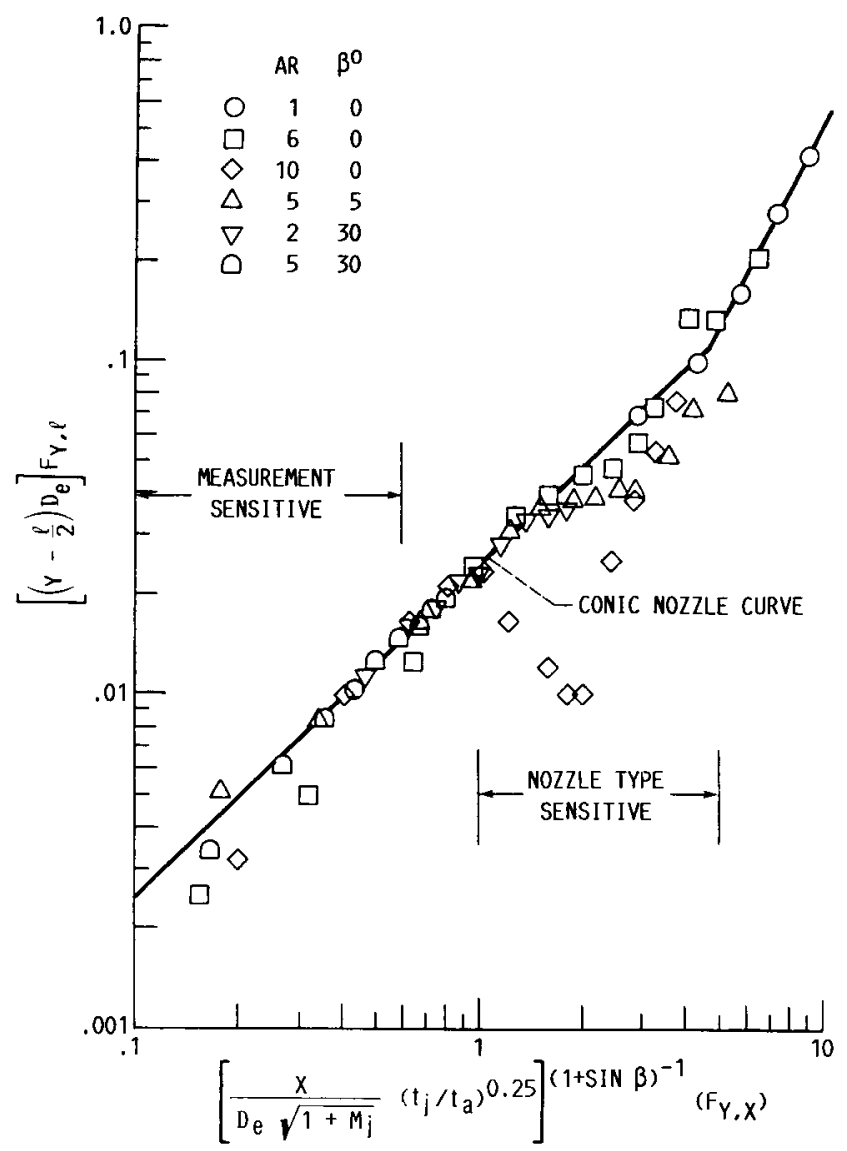

FIGURE 34. - CORRELATED LOCAL PLUME HALF-VELOCITY $\left(U_{C} / 2\right)$ IN NOZZLE WIDTH (Y) DIMENSION. 


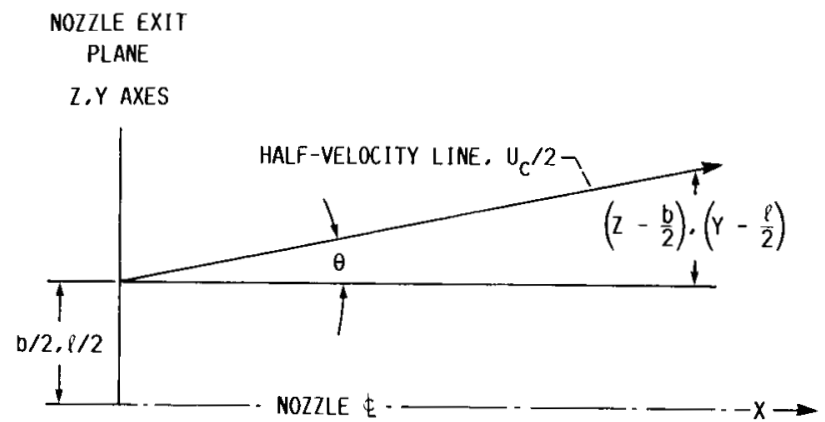

(A) OVERALL PLUME HALF-VELOCITY SPREADING ANGLE.

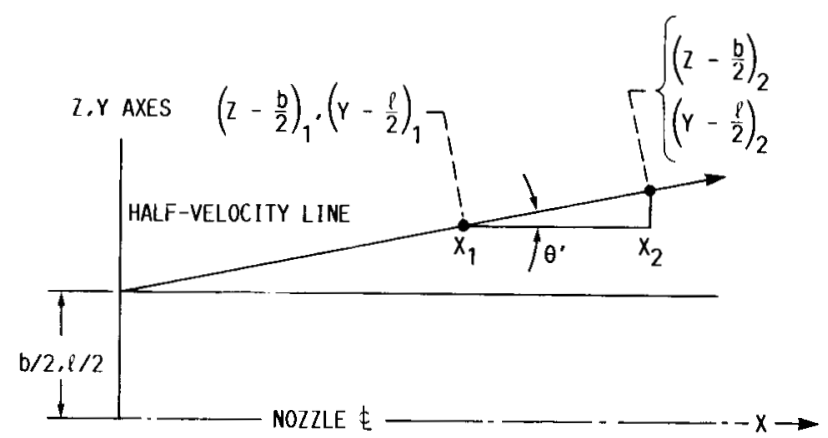

(B) LOCAL PLUME HALF-VELOCITY SPREADING ANGLE.

FIGURE 35. - SCHEMATIC SKETCH OF PLUME HALF-VELOCITY SPREADING ANGLE.

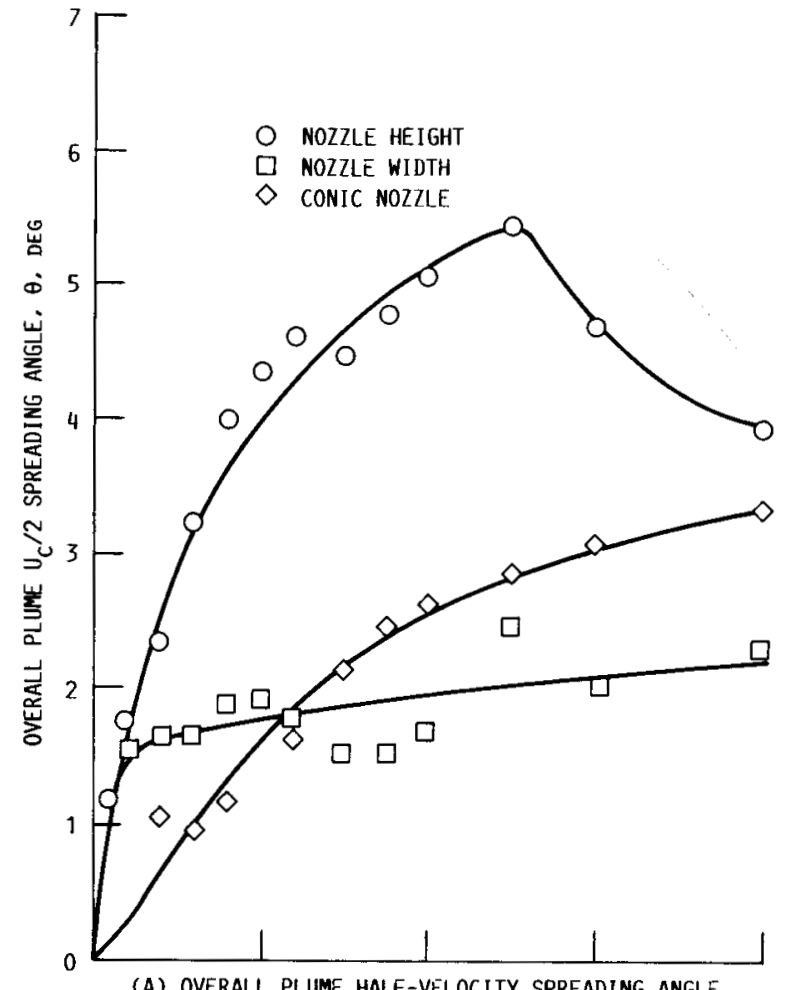

(A) OVERALL PLUME HALF-VELOCITY SPREADING ANGLE.

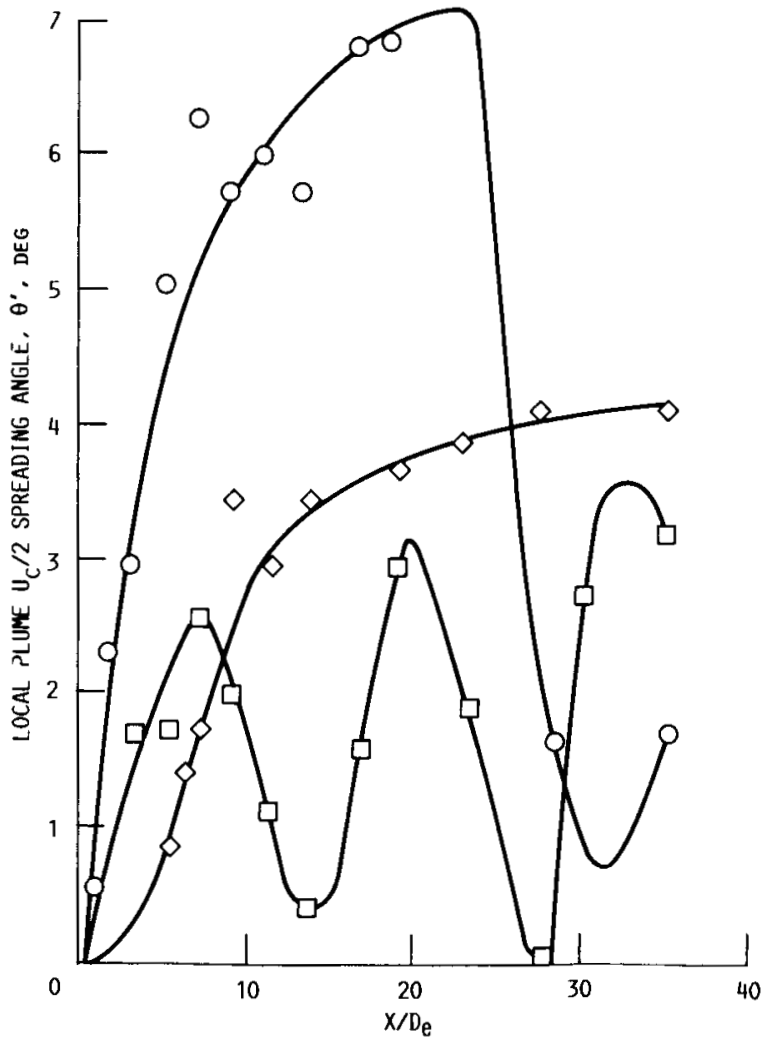

(B) LOCAL PLUME HALF-VELOCITY SPREADING ANGLE.

FIGURE 36. - REPRESENTATIVE TWO-DIMENSIONAL NOZZLE PLUME HALF-VELOCITY SPREADING ANGLE CHARACTERISTICS. REFERENCE 19 DATA; AR, 6; COLD FLOW; NOMINAL Mj, 0.8 . 


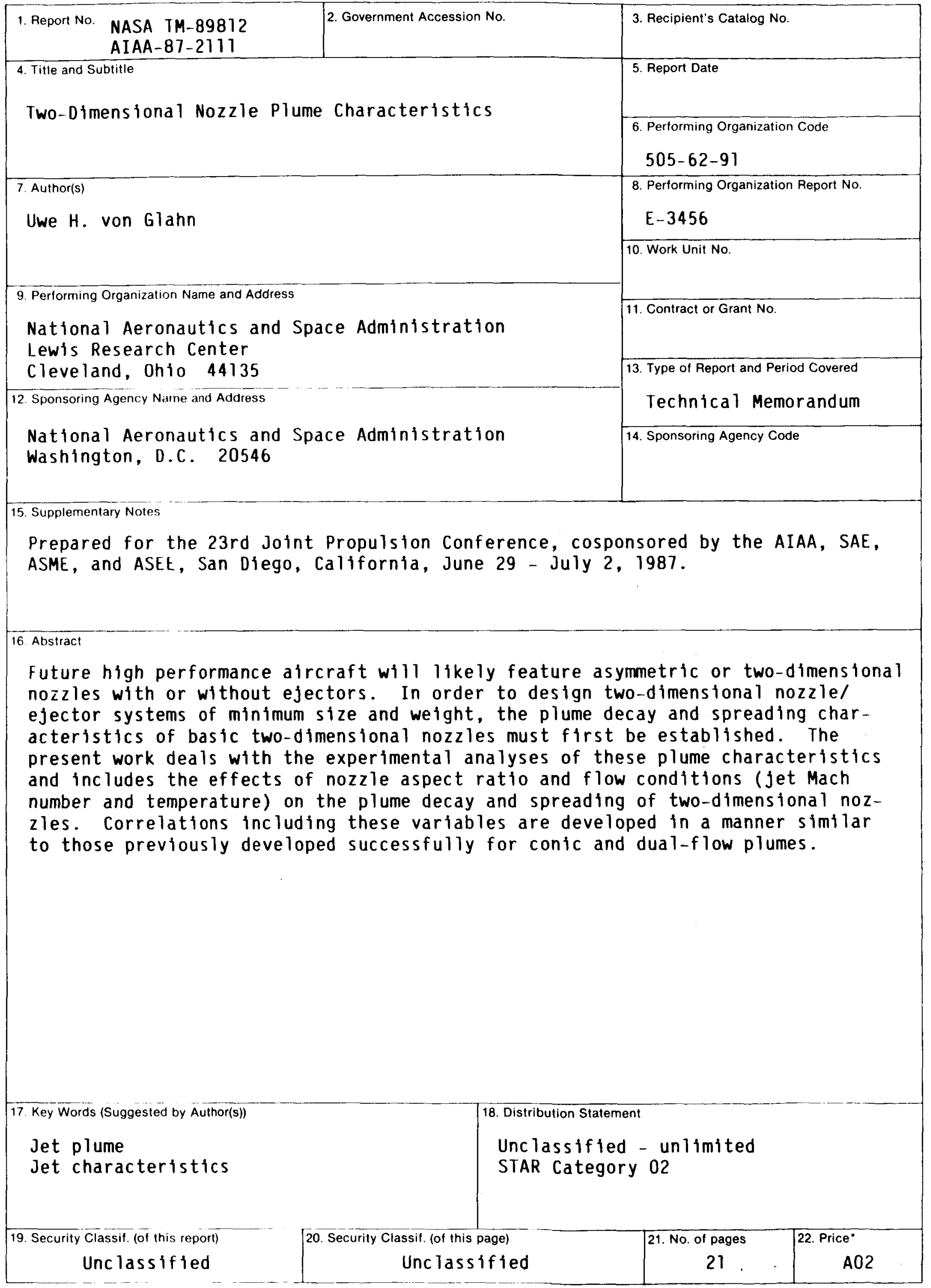

"For sale by the National Technical Information Service, Springfield, Virginia 22161 